\title{
Household Spending Patterns and Hardships during COVID-19: A Comparative Study of the U.S. and Israel
}

\author{
Stephen Roll ${ }^{1}$ - Yung Chun ${ }^{2} \cdot$ Olga Kondratjeva $^{3} \cdot$ Mathieu Despard $^{4} \cdot$ Talia Meital Schwartz-Tayri $^{5}$. \\ Michal Grinstein-Weiss ${ }^{1}$
}

Accepted: 28 November 2021 / Published online: 27 January 2022

(C) The Author(s), under exclusive licence to Springer Science+Business Media, LLC, part of Springer Nature 2021

\begin{abstract}
The combined supply and demand shocks of the COVID-19 pandemic have created the largest consumer behavior shift in recent history, while exposing millions of households to material hardships like food insecurity and housing instability. In this study, we draw on national surveys conducted early in the pandemic to investigate the pandemic's effects on selfreported consumer spending behaviors and experiences of hardship for households in the US and Israel; two countries that are similar in terms of their development but have had divergent experiences with and responses to the pandemic. We also examine the extent to which racial/ethnic/religious minority status and pre-pandemic employment characteristics predict these outcomes. Using descriptive and logistic regression approaches, we find that housing expenditures were fairly stable in the U.S. and Israel, while food and credit card payment expenditures were relatively volatile. We also find that skipped utility bill payments were much higher in the US than Israel, while rates of skipping housing payments and food insecurity were similar between the two countries. Generally speaking, racial/ethnic/religious minorities in both countries were more likely to experience spending volatility, while Black and Hispanic (in the US) and Arab (in Israel) households were more likely to experience hardships. Employment and financial characteristics also appeared much more predictive of hardship in the US than in Israel.
\end{abstract}

Keywords COVID-19 · Material hardship · Comparative analysis · Consumer behavior · Israel · United States

This is one of several papers published together in Journal of Family and Economic Issues on the "Special Issue on the Social and Economic Impact of Covid-19 on Family Functioning and Well-Being".

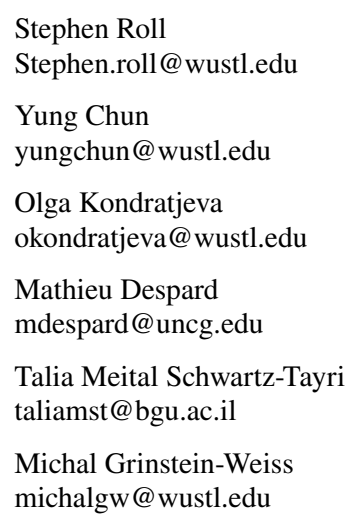

\section{Introduction}

The COVID-19 pandemic has created the largest shift in consumer behavior in recent history (Brinca et al., 2020; Triggs \& Kharas, 2020). On the demand side, widespread and sudden income declines from job loss or reduced work hours have led to expenditure declines for many

1 Social Policy Institute, Brown School, Washington University in St. Louis, St. Louis, USA

2 Social Policy Institute, Washington University in St. Louis, St. Louis, USA

3 Washington State Employment Security Department, Olympia, USA

4 Department of Social Work, University of North Carolina Greensboro, Greensboro, USA

5 Social Work Department, Ben Gurion University of the Negev, Beersheba, Israel 
non-essential purchases and forced many families to forgo basic needs like food or housing payments. Additionally, greater reliance on unemployment insurance benefits or one-time economic support payments have changed how and when households decide to spend their income. Consumer spending preferences have also changed dramatically, shifting away from activities that may expose individuals to greater health risks-such as going to the gym or dining out - toward activities with limited risks such as dining or exercising at home.

On the supply side, government decisions have directly influenced consumer behaviors by restricting activities that may lead to greater viral spread. For example, restrictions that mandate business closures, hour restrictions, or occupancy have changed how consumers shop and spend. Similarly, lockdowns and changes in work environments mean that many transitioned to spending both their work and leisure hours at home.

The effects of all these factors operating simultaneously on consumer behavior are ambiguous. It is unclear whether, and to what extent, the supply- and demand-side shifts have affected consumer spending on essential needs like food, rent, and bills, as there are many competing pressures on these spending behaviors. For example, job losses and eviction moratoria may decrease spending on rent, but social distancing may compel households to seek separate living arrangements. Similarly, food spending may have decreased due to limitations on dining out or it may have increased because parents had to provide meals their children would have received at school. Moreover, these effects are likely not uniformly distributed in the population, and instead may be influenced by differences in household income, employment stability, and other economic security measures. While the aggregate effects of these shifts in consumption may be ambiguous, the overall toll of the pandemic on many indicators of household financial security is not, as many households face higher risks of unemployment, impoverishment, and hardship (Despard et al., 2020; Egger et al., 2021; Organization for Economic Cooperation and Development [OECD], 2020a, b, c).

In this study, we investigate the pandemic's effects on self-reported consumer spending behaviors and experiences of hardship for households in two countries that have had divergent experiences with, and responses to, the pandemic: the US and Israel. Though the two nations differ in population size, they are both OECD countries with advanced economies and similar rates of economic inequality and poverty (OECD, 2021a, b). They also generally exhibited very similar per capita COVID-19 infection rates through much of 2020 (Ritchie et al., 2021), as well as similar GDP declines relative to the same quarter in 2019 , which were smaller than the declines in many other advanced economies (Hasell, 2020). Despite these similarities, the US experienced a dramatically sharper increase in unemployment in the early months of the pandemic, compared to Israel OECD, 2021c), and the countries also differed substantially in their policy responses to the pandemic's economic effects. It is within the context of these similarities and differences that we situate this comparative analysis.

A growing body of research documents the impacts of the COVID-19 pandemic on consumer spending behaviors and hardship indicators at the macro-level (OECD, 2020b), in the U.S. and more broadly. However, there has been limited research on changes in consumer spending and hardships during the pandemic at the household level, and how these changes differ across countries. To fill this gap, we leverage two unique national surveys administered in the U.S. and Israel to investigate households' reported changes in spending behaviors and their experience of material hardships during the pandemic's early months. These surveys were developed through a partnership between US and Israeli researchers as part of an effort to identify differences and similarities in the socio-economic impacts of the pandemic across the two countries, and were administered over similar time periods and used similar sampling strategies and survey modalities, which facilitate cross-country comparison. Using a combination of descriptive approaches, binary logistic regression, and multinomial logistic regression, we examine the following research questions:

- To what extent did households in the US and Israel report shifting expenditures during the early months of the COVID-19 pandemic?

- What was the experience of material hardships during the early months of the COVID-19 pandemic in the US and Israel?

- How do key household characteristics, such as racial/ ethnic/religious minority status, income, employment status, and the experience of COVID-19-related job loss, relate to consumer spending patterns and the experience of hardship in each country?

By investigating both spending behavior and the experience of hardships during the early months of the COVID19 pandemic, our analysis contributes to the literatures on economic analysis and consumer financial decision making in the context of large-scale economic shocks. Moreover, drawing on surveys capturing household experiences around the time that unemployment claims peaked in both countries allows us to chronicle the consumer impacts of the pandemic when they were likely most severe. Lastly, the comparative nature of work, which examines consumer behaviors during COVID-19 in both the US and Israel, allows us to explore how the experience of the pandemic differed between two OECD countries with different experiences of COVID-19. Exploring commonalities and differences between countries 
allows us to document how national contexts can influence households' resilience to large-scale shocks like the COVID19 pandemic, which is important in preparing for future shocks and identifying avenues through which policymakers can help households recover from the current crisis.

\section{Background}

\section{COVID-19 and Policy Responses in the U.S. and Israel}

\section{United States}

On January 21, 2020, the first confirmed case of COVID-19 appeared in the US, and 10 days later the federal government declared a public health emergency. ${ }^{1}$ Throughout March and April, as U.S. states began imposing stay-at-home orders and other measures meant to curb the spread of the virus, the unemployment rate rose to record levels, peaking at $14.8 \%$ in April, 2020. Initial unemployment claims during the pandemic remained extraordinarily high over the ensuing months and, despite some stabilization by the summer of 2020, remained elevated throughout 2020 and early 2021.

The U.S. policy response to COVID-19 has included several major pieces of federal legislation and actions by the executive branch, supplemented by local and state policy actions. We highlight the major federal responses that occurred during the onset of the pandemic, during roughly the same timeframe as our study, and which may have had implications for the consumption behaviors and hardships that are the focus of this study. The first major federal legislative response was the Families First Coronavirus Response Act, enacted on March 18, 2020. In addition to providing funds to cover testing and other public health needs, this bill provided additional funds for food support programs as well as the unemployment insurance system, and expanded the definition of paid sick leave to encompass COVID19-related illnesses or related issues (e.g., being subject to quarantine) (Moss et al., 2020). The second major COVID19-relief bill- the Coronavirus Aid, Relief, and Economic Security Act (the CARES Act)—was passed shortly thereafter and included: (1) direct assistance for U.S. households through Economic Impact Payments, which offered up to $\$ 1200$ per adult and $\$ 600$ per child in a household; (2) loans and grants to businesses under the Paycheck Protection Program, as well as other incentives for businesses to retain workers; (3) the Emergency Rental Assistance program to help households unable to pay their rent and utilities during

\footnotetext{
1 The timeline of the events and policy responses in this section are drawn from the St. Louis Federal Reserve's FRASER (Federal Reserve Bank of St. Louis, 2021), unless otherwise noted.
}

the pandemic; and (4) additional unemployment payments of $\$ 600$ per week for households receiving unemployment benefits (Treasury Department, 2021). In addition to these supports, the CARES Act also imposed a federal eviction moratorium intended to keep families in their homes and stop the potential spread of COVID-19 that may accompany a family being evicted. This moratorium ran from late March to late July of 2020, and was later extended by an eviction moratorium from the Centers for Disease Control (Congressional Research Service, 2021). The federal eviction moratoria were complemented by an array of state-based moratoria on utility disconnections due to non-payment of bills, which had a similar aim of keeping families in their homes during the pandemic (National Association of Regulatory Utility Commissioners, 2021).

Though the federal government provided guidance on social distancing restrictions, the decision to formally restrict different individual and business activities was left up to the states. As such, the restrictions on consumer behaviors imposed by individual states ranged from the relatively minimal (e.g., South Dakota) to the relatively strict (e.g., California, New York). In general, states tended to impose restrictions on recreational- or entertainment-oriented businesses such as gyms and movie theaters, and non-essential activities where social distancing was unlikely, such as dining-in at restaurants or going to bars.

\section{Israel}

Similar to the US, Israel imposed a number of restrictions in conjunction with relief programs that may have impacted the consumption behaviors and household hardships. Following the first confirmed case of COVID-19 on February 21, 2020, the Israeli government enforced aggressive social distancing measures, tightening existing restrictions and declaring a national state of emergency at the end of March. Israel pursued a national strategy to curb the spread of the virus by placing limitations on employment and business activities and restricting consumer behaviors. For example, the movement of residents was limited to no more than $100 \mathrm{~m}$ from their place of residence, the number of employees in a workplace and public gatherings was restricted, residents were required to wear face coverings in public, and many businesses, with the exception of essential services, were shut down (Ministry of Health, 2020a, b; OECD, 2020c).

As a result of these restrictions, businesses and entities across a wide spectrum of sectors in Israel experienced a severe slowdown during March and April, 2020. Approximately a third of the economy was shut down at the height of the lockdown (OECD, 2020c). In April, 39\% of employed individuals were not able to work due to COVID-19, which decreased to $24.4 \%$ in May (Central Bureau of Statistics, 2020a). Following the continued rise in the COVID-19 
cases, further restrictions and measures were put into effect in July, 2020.

During the early months of the pandemic, Israeli policymakers developed multiple policies and financial assistance programs to consumers to alleviate the negative impacts of COVID-19. First, in the wake of the pandemic, the Israeli government considerably expanded the unemployment insurance (UI) program to mitigate the financial burden of the pandemic on households by, for example, extending eligibility for unemployment benefits to June, 2021, shortening the benefit qualification period, and offering unemployment support to elderly workers and qualifying self-employed workers (National Insurance Institute [NII], 2020). Second, the government has implemented several financial assistance programs. For example, additional financial support via several funding rounds to qualifying self-employed workers who experienced a severe reduction in their self-employment activities and whose incomes did not exceed a certain threshold. Similarly, the government offered compensation to employers for the workers' time in quarantine and provided a work injury grant to workers who were exposed to COVID-19 at their workplace (NII, 2020). Third, in April, 2020, the government provided a one-time small cash payment of NIS $500^{2}$ (USD 142) per person to eligible families with children, the elderly, and other vulnerable household members. Other economic relief measures to help consumers mitigate the consequences of the pandemic included assistance with electricity bills, bans on foreclosures, and deferrals and payment reorganization of mortgage and loan payments (KPMG, 2020).

Overall, the adopted measures-which were relatively similar to the responses implemented in the US (though they differed in their intensity and scope)—were expected to mitigate the adverse effects of the pandemic on financial outcomes and consumer behaviors.

\section{The Consumer Impact of the COVID-19 Pandemic in the U.S. and Israel}

\section{United States}

Similar to other large-scale economic crises, the ongoing crisis caused by the COVID-19 pandemic is characterized by high unemployment levels. At the same time, the current crisis is differentiated from others by its concurrent supply and demand contractions (Brinca et al., 2020); concentrated impacts on certain populations including women, racial/ ethnic minorities, and frontline workers (Hardy \& Logan, 2020; Long et al., 2020; Tomer \& Kane, 2020); government

\footnotetext{
2 NIS = Israeli New Shekel. Exchange rates correspond to June 1,
} 2020 (USD $1=$ NIS 3.51). mandates to restrict business and consumer activities; and a broad-based, global shift in consumer spending preferences (McKinsey \& Company, 2020).

During the COVID-19 pandemic, personal consumption expenditures (PCE) - an indicator of consumer spending based on the value of goods and services purchased by U.S. residents-dropped by $9.6 \%$ in the second quarter of 2020 as unemployment spiked, but rebounded with an $8.9 \%$ increase in the third quarter. Spending on durable and non-durable goods was $6.7 \%$ and $4.0 \%$ higher in the third quarter of 2020 compared to the fourth quarter of 2019 , respectively, while spending on services was $7.7 \%$ lower. The decline in spending on services has been sharp for services involving public gatherings and face-to-face contact, such as food services, accommodations, recreation, and transportation. Conversely, spending on non-contact services such as financial services remained steady (Bachman et al., 2020), while spending for store purchases of food and beverages increased (Dunn et al., 2020).

Mounting evidence documents the adverse effects of the pandemic on financial security of U.S. households. High percentages of households reported struggling to pay their bills, relying on their savings to make ends meet, and receiving food assistance (Parker et al., 2020). With the unemployment rate almost quadrupling in the span of 2 months (Kochhar, 2020), households who lost their jobs due to the COVID-19 pandemic were two to three times more likely to experience hardships including skipped housing payments, skipped medical care, and food insecurity (Despard et al., 2020). Though the pandemic's impacts on U.S. consumers have been broad-based, they were acutely felt in more economically vulnerable populations and among racial/ethnic minority groups. Households with low pre-pandemic incomes were more likely to experience COVID-19-related job or income losses (Despard et al., 2020) and report an array of housing hardships (e.g., eviction and housing/utility payment delinquencies) as a result of the pandemic (Chun et al., 2020). Those with low levels of liquid assets prior to the pandemic were also much more likely to report experiencing financial hardships or using high-cost financial resources (e.g., payday loans) after facing a COVID-19-related income shock, compared to households with relatively high levels of pre-pandemic liquid assets (Roll \& Despard, 2020). Finally, the consumer impact of COVID-19 intersects with racial and ethnic inequality. Employment has dropped the most in low-wage occupations-which are disproportionately held by Black and Hispanic workers-compared to middle- and high-wage occupations. Correspondingly, racial/ethnic minority households were more likely to experience hardships during the pandemic including food insecurity (Morales et al., 2020) and housing instability (Chun et al., 2020). 


\section{Israel}

Similar to the US, the pandemic has shifted consumer behaviors in Israel. Private consumption expenditures by Israeli households dropped over the first two quarters of 2020 before rebounding in the third quarter (Central Bureau of Statistics [CBS], 2020b). Changes in economic activities and consumer preferences were heterogeneous across different spending categories. The hardest hit sectors were those most affected by social distancing measures, such as the service industry, tourism, transportation, and entertainment (Dun $\&$ Bradstreet, 2020). In addition, credit card spending data shows that while household spending on travel, apparel, and leisure dropped precipitously during the initial lockdown, spending on food, electronics, and insurance increased (Dovrat-Meseritz, 2020).

Evidence shows that strict social distancing measures and social isolation may have had a profound impact on financial security of households. For example, households experienced heightened rates of household hardship during the pandemic in Israel. Specifically, the share of households living in poverty increased from 20.1 to $29.3 \%$ over the year (Latet, 2020) and the majority of households surveyed by CBS in July, 2020 said that they were worried about not being able to meet their monthly expenses (CBS, 2020c). Furthermore, food insecurity has increased (CBS, 2020c; Laufer et al., 2020) with rates jumping from 17.8 before the pandemic to $22.6 \%$ during the pandemic, and the number of households reporting financial hardship rising from 24.1 to $38.6 \%$ (Latet, 2020). The majority of respondents surveyed in August, 2020 reported income declines during the pandemic, with almost a quarter of respondents reporting significant income reductions (Laufer et al., 2020). Correspondingly, most respondents also said that they had to cut their expenses due to the pandemic and their ability to meet monthly expenses has decreased, with nearly a quarter reporting that the expense cuts have affected their lifestyles to a greater degree (Laufer et al., 2020).

Hardship and adverse experiences were disproportionately felt in more economically vulnerable populations. Religious/ethnic minorities were more likely to report that they could not afford adequate food and skipped bill payments as a result of the pandemic (Kondratjeva et al., 2021), reported lower access to liquidity and higher rates of denial of government benefits (Social Policy Institute, 2020). Furthermore, the reductions in income and expenses were more pronounced among households with lower pre-COVID-19 incomes and single-headed households (Laufer et al., 2020).

While the adverse effects on consumption behaviors and financial security are well-documented, much less is known about how government support was used to help households overcome the adversities of the pandemic. Some descriptive evidence shows that households receiving unemployment benefits also experienced higher incidence of hardship, although the rates of hardship between those receiving and not receiving financial support by differed based on household income (Kondratjeva et al., 2021). That is, the reported incidence of hardship between unemployment benefits recipients and non-recipients was not significantly different for the lowest income households, though rates differed for the middle-income group. Another study documenting the use of a one-time cash payment disbursed in August, 2020 suggests that the most frequent uses of small grants were debt repayment ( $45 \%$ of survey takers), spending (25\%), saving $(16 \%)$, and donating or providing assistance to friends and families (14\%) (Feldman \& Heffetz, 2021).

\section{Financial Shocks, Consumer Spending, and Household Hardship}

A large literature describes how the most recent example of a large-scale, global economic shock-the Great Recession of 2007 to 2009-changed consumer behaviors. This evidence shows that consumer spending in the US dropped in all categories during the recession and remained below pre-recession levels for a longer period of time than in prior recessions (Petev \& Pistaferri, 2012). As a whole, OECD countries experienced a drop in private consumption, and most countries saw similar changes in expenditures over time (Lequiller \& Blades, 2014).

Overall, household consumption responses to economic crises may vary based on household financial characteristics and distress. For example, lower consumer spending during the Great Recession was associated with greater household debt (Dynan \& Edelberg, 2013; Dynan et al., 2012; Mian et al., 2013). Krueger et al. (2016) found that households in the bottom two-fifths of the wealth distribution experienced a larger dip in aggregate consumer spending than higherwealth households.

Evidence from the Great Recession further shows that the financial crisis led to steep declines in economic output and substantial increases in unemployment around the world (United Nations Department of Economic and Social Affairs, 2011). The crisis subsequently resulted in higher poverty rates and, commensurately, increased rates of food insecurity (Coleman-Jensen, 2012), indicators of housing instability (Hurd et al., 2010), and rates of skipping bills and utility shutoffs (Pilkauskas et al., 2012).

In addition to research on the impact of large-scale financial shocks, a large body of literature focuses on the relationship between household-level financial shocks-i.e., large and unanticipated income declines or expense increases experienced by households (Chase et al., 2011) —and household hardship. Research in the US demonstrates that financial shocks are common, with over $60 \%$ of households experiencing at least one shock in a given year (Abbi, 2012), 
and costly, with the average cost of a financial emergency estimated to be between $\$ 1500$ and $\$ 2000$ (Collins \& Gjertson, 2013; Searle \& Köppe, 2014). These shocks generally expose households to higher risks of hardships, including food insecurity, falling behind on utility bills or housing payments, and skipping essential medical care (e.g., Despard et al., 2018; Heflin, 2016). Beyond these short-term issues, hardships expose households to a wide array of long-term adverse outcomes, including physical and mental health issues (Heflin \& Iceland, 2009; Whittle et al., 2015), housing instability (Desmond \& Kimbro, 2015), and child developmental problems (Rauh et al., 2004).

The aforementioned research on the impact of economic shocks tends to focus purely on economic phenomena. That is, it investigates the income, expense, and balance sheet impacts of economic shocks, and how these translate into household experiences of hardship in the short- and longterm. However, the COVID-19 pandemic is fairly unique in that it combined a large-scale economic shock with the high levels of psychological stress, fear, and uncertainty that accompany natural disasters and other similar events. Researchers have become increasingly interested in the impact of these events on consumer behavior, which often results in consumers engaging in "panic buying" of various products. In a systematic review of research on panic buying, Yuen et al. (2020) identified four major causes of panic buying: perceptions of threat or scarcity, fear of the unknown, coping behaviors, and social psychological factors like social influence and social trust. Some of these motivations can be seen as individually rational. For example, panic buying or hoarding behavior can have self-protective effects and can help minimize risk (Sheu \& Kuo, 2020) or maintain a sense of freedom (Gupta \& Gentry, 2016). However, it may also be a response to social, psychological, or emotional factors like anxiety (Kemp et al., 2014), a feeling of lost control (Sneath et al., 2008), or a fear of missing out on some essential purchase a person may need in the future (Kang et al., 2020). Each of these factors may have led to increased volatility in spending on both essential and non-essential goods during the pandemic, as households responded to increasingly volatile economic, social, and public health conditions.

Much as unexpected job and income losses are associated with the experience of material hardship and other negative effects on household well-being, volatility in expenditures can also have well-being implications for households. For example, one study found that after a large increase in expenses, an individual's liquid assets remained low for 1 year following the expense while their debt remained elevated (Farrell \& Greig, 2017), and large and unexpected expenses have been linked with both household and child food insecurity (Bartfeld \& Collins, 2017). More generally, expense volatility has been linked to modest declines in a household's subjective sense of financial well-being (Bufe et al., 2021).

\section{Contribution of the Current Study}

Prior research identifies the effects of large-scale macroeconomic shocks on households, drawing most recently on experiences during the Great Recession of 2007-2009. The COVID-19 pandemic, with its simultaneous demand and supply side economic shocks, acting in concert with a large-scale global public health crisis that caused a high degree of fear and uncertainty, presents new challenges facing households. As such, research on the consumer impact of the COVID-19 pandemic on households is growing. Our study contributes to this body of knowledge in unique ways. First, we simultaneously examine changes in household expenditures and households' experiences of material hardship whereas most studies only examine hardship prevalence. To examine this relationship, we use retrospective questions covering the period just before the beginning of the pandemic through the early months of the pandemic when unemployment was highest. We also employ a robust set of controls in addition to demographic characteristics and income, including credit card and bank account ownership, health insurance, assets, and a range of employment situations including job loss, traditional employment, selfemployment, and gig work. Second, we compare household experiences in two OECD countries that experienced the same global event using very similar sampling strategies and research methods. We compare the degree to which household characteristics account for variation in economic impacts in each country, including impacts on racial/ethnic/religious minority groups to assess disparities. In these respects, we dig deeper into data to more comprehensively understand the economic impacts of the COVID-19 pandemic on households.

\section{Data}

The empirical analysis in this study is based on the SocioEconomic Impacts of COVID-19 Survey (Roll et al., 2021), which was administered to adult respondents in both the US and Israel through a partnership between research institutions in both countries. Through a large online survey platform, ${ }^{3}$ the Social Policy Institute at Washington University in St. Louis administered the survey from April 27, 2020,

\footnotetext{
${ }^{3}$ Research has demonstrated that online, non-probability samples using Qualtrics panels, the online panel used in this study, generate samples that closely approximate those of the General Social Survey, which is considered the gold standard in survey administration (Zack et al., 2019).
} 
to May 12, 2020, in the U.S. and from June 4, 2020, to July 1,2020 , in Israel. The gap in survey administration periods was due to fact that the Jewish holiday season in Israel began in April of 2020, and the researchers elected to field the Israeli survey immediately after the end of this season in order to ensure representation of large religious groups such as Ultra-Orthodox Jews in the survey. ${ }^{4}$ Both the U.S. and Israeli surveys collected information on demographic characteristics, employment, debt and assets, experience of material and medical hardships, health status, government benefits, and attitudes towards the COVID-19 pandemic.

Each survey sample was developed using targeted quota sampling techniques to ensure that the sample represented each country's demographic characteristics. In the US, the sampling quotas were constructed to approximate U.S. Census estimates (based on the 2019 American Community Survey) of national population distributions in terms of gender, age, race/ethnicity, and income. In Israel, Jewish respondents were sampled using four demographic quotas (gender, age, income, and religiosity) so that our sample reflected the Jewish adult population (based on CBS data). Arab Israeli respondents were selected without applying sampling criteria, because generational and gender differences in access to technology in Arab communities may complicate the use of targeted sampling in an online survey of Arab Israelis. In the U.S., the survey response rate was $10.8 \%$. In Israel, the survey response rate was $16.4 \% .^{5}$ After the screening and cleaning process, ${ }^{6}$ the final analytical sample is 4,684 and 1,889 in the U.S. and Israel data, respectively.

\footnotetext{
4 The fact that the time periods of the surveys do not overlap perfectly may raise concerns about the comparability of the studies. However, we do not anticipate this being a major concern because all of the relevant outcome measures in this study are retrospective and thus cover the acute periods of the economic crisis in both countries. Nevertheless, the fact that the Israel survey was implemented a month after the U.S. survey represents a limitation of this study.

5 Survey response rates were calculated using the American Association for Public Opinion Research's RR2 measure, which includes respondents who took part in the survey but were later excluded due to quota requirements (American Association for Public Opinion Research, 2016).

${ }^{6}$ In total, 16,200 respondents entered the U.S. survey and 3,084 entered the Israel survey. The survey excluded respondents who failed to meet quota requirements to ensure national representativeness on the established sampling criteria and/or quality checks embedded in the survey. In addition to the survey screening, we excluded those who did not provide a response to the items used in this analysis using listwise deletion.
}

\section{Methods}

\section{Measures}

This study explores the changes in household expenditures and material hardship experiences during the first months of the COVID-19 pandemic. We measure the changes in household expenditures during the pandemic with respect to essential needs including housing (rent or mortgage payment), utilities, and food, as well as their credit card debt payments. With respect to each of the essential needs, respondents were asked "how does your household spending over the last month compare to your household's spending 3 months ago?" Per each essential need, respondents chose one of four possible answers ("spending increased," "no change in spending," "spending decreased," "not applicable"). Per credit card debt payments, respondents were asked "How would you say your household's credit card debt has changed compared to 3 months ago?", and they could select one of five categories ("greatly increased," "somewhat increased," "no change," "somewhat decreased," "greatly decreased"). For the sake of comparability, we recoded each expenditure variable into three categories: (1) spending/debt amount increased; (2) no change in spending/debt amount; (3) spending/debt amount decreased. Respondents who selected "not applicable" for any of the expenditure categories, or who did not own a credit card, were excluded from the analyses of that respective outcome measure.

To assess the experience of material hardships, we include three measures: skipped rent/mortgage payment, skipped utility payment, and food insecurity. For the first two hardship measures, both surveys in the US and Israel asked if the respondent's household had skipped a rent/mortgage or utility payment in the past 3 months. To construct a food insecurity measure in the US, we utilized three food security-related questions from the USDA's food insecurity scale asking if the household (1) didn't have money to get food, (2) couldn't afford to eat balanced meals, or (3) cut the size of meals or skipped meals in the past 3 months because they did not have enough money for food (USDA Economic Research Service, 2012). We coded the food insecurity variable as ' 1 ' if a respondent answered positively for any of the three questions - otherwise, the variable was coded as a ' 0 '. In Israel, the survey included a single question on food insecurity asking if the respondent's household could not afford the type or amount of food they needed in the past 3 months.

Notably, these material hardship measures were not specific to the COVID-19-pandemic. That is, we asked about the general experience of hardships rather than hardships caused by the COVID-19 pandemic. However, for each of these categories of hardships, we did ask an equivalent question capturing the extent to which a given hardship was 
attributable to the pandemic (e.g., "When your household did not pay the full amount of the rent or mortgage, was this due to financial issues caused by the COVID-19 pandemic?" in the U.S. survey-see Table A1 in the Appendix for a summary of all questions). We include the results of the models using these COVID-19-specific variables as a supplemental analysis.

To investigate the relationship between these expenditure and hardship measures and key household characteristics in the US and Israel, we draw on an array of survey questions capturing households' composition, finances, demographics, and experiences both before and during the pandemic. While the U.S. and Israeli surveys are highly similar and were administered in similar timeframes, some questions were adjusted to fit the local context of each country. An emblematic difference concerns the questions on race/ethnicity and religion in the two countries. In the US, we categorized the sample into five groups-non-Hispanic White (hereafter White), non-Hispanic Black (hereafter Black), non-Hispanic Asian (hereafter Asian), Hispanic, and others. In Israel, the demographic characteristics of the population are commonly described not by race and ethnicity, but by religion/religiosity and ethnicity; hence we categorized the sample into four groups-non-Ultra-Orthodox Jews, UltraOrthodox Jews, Arab Israelis, and others.

In addition to the measures of race/ethnicity and religion/ ethnicity, our empirical models take into account demographic characteristics (gender, age, living arrangement, educational attainment, and the number of dependents), employment (respondent's and spouse/partner's employment status, having side or gig jobs, COVID-19-related job/ income loss), income and assets (monthly family income in $2019,{ }^{7}$ having access to financial resources in the event of an emergency, having credit cards, having a bank account, and having health insurance). Though the wording of some survey questions and response categories vary somewhat between the U.S. and Israeli surveys, all the questions and possible answers in both surveys are comparable to each other (see Table A1 in the Appendix).

Finally, while each of the outcome measures in this study captures experiences during the early months of the COVID19 pandemic, many of the questions we use to measure key household characteristics are explicitly framed to identify a

\footnotetext{
7 In the U.S., pre-pandemic monthly income was asked as a continuous variable, while in Israel it was asked as a categorical variable with categories of NIS 0-8000, NIS 8001-17,000, and NIS 17,001+. To make the incomes comparable between the two countries, we created low/middle/high-income categories for the U.S with distributions that roughly correspond to the distributions of the Israel categories (see Table A2 in the Appendix). Our U.S. definitions of low, middle, and high-income in the U.S. are \$0-3000, \$3001-8000, and $\$ 8001+$, respectively.
}

household's situation before the pandemic. For example, our income measure asks about pre-pandemic household income and our employment measures ask about the respondent's employment status 3 months prior (i.e., before the start of the pandemic). At the same time, some questions, such as the experience of job/income loss as a result of the pandemic, are intentionally framed in a way to capture a household's situation during the pandemic.

\section{Empirical Model}

This paper explores the associations between household characteristics, expenditure patterns, and hardship experiences during the early months of the pandemic. As the four expenditure variables allow three outcomes-expenditures increased/decreased/not changed-we employ a multinomial logit (MNL) model of the following general form:

$$
\begin{aligned}
& \ln \left(\frac{\operatorname{Pr}\left(Y_{i}=\text { Increased }\right)}{\operatorname{Pr}\left(Y_{i}=\text { NoChange }\right)}\right)=\beta_{0}+\beta_{1} X_{i}^{\text {Demo }}+\beta_{2} X_{i}^{\text {Emp }}+\beta_{3} X_{i}^{\text {Fin }} \\
& \ln \left(\frac{\operatorname{Pr}\left(Y_{i}=\text { Decreased }\right)}{\operatorname{Pr}\left(Y_{i}=\text { No Change }\right)}\right)=\beta_{0}^{\prime}+\beta_{1}^{\prime} X_{i}^{\text {Demo }}+\beta_{2}^{\prime} X_{i}^{\text {Emp }}+\beta_{3}^{\prime} X_{i}^{\text {Fin }}
\end{aligned}
$$

where $\operatorname{Pr}(\cdot)$ is the logistic probability function. $X^{D e m o}$ is a vector including gender, age, living arrangement, educational attainment, and the number of dependents; $X^{\text {Emp }}$ encompasses employment characteristics during the pandemic, such as respondent's and spouse/partner's employment status, having gig or side jobs, and COVID-19-related job/income loss; and $X^{\text {Fin }}$ includes financial characteristics, such as pre-pandemic monthly household income, asset liquidity for an emergency before the pandemic, and owning credit cards, a bank account, or health insurance (in the U.S. only). The coefficients report the odds ratios of the increase or decrease in each expenditure category relative to the baseline outcome (no changes in an expenditure category) during the pandemic. We estimate the model via maximum likelihood.

We employ a logistic regression model to explore the relationships between binary material hardship experiences and the key independent variables listed above. Our binary logistic model can be expressed formally as:

$$
\ln \left(\frac{\operatorname{Pr}\left(Y_{i}=1\right)}{\operatorname{Pr}\left(Y_{i}=0\right)}\right)=\beta_{0}^{\prime \prime}+\beta_{1}^{\prime \prime} X_{i}^{D e m o}+\beta_{2}^{\prime \prime} X_{i}^{E m p}+\beta_{3}^{\prime \prime} X_{i}^{F i n}
$$

here the coefficients estimate the odds ratios of a given material hardship experience relative to the baseline outcome of no hardship experience.

In the main analysis, we only present coefficient estimates for variables that capture respondents' race/ethnicity and religion, pre-pandemic household income, and pre-pandemic 
employment characteristics, as these indicators have been identified as potentially significant predictors of exposure to COVID-19-related financial issues (Despard et al., 2020; Hardy \& Logan, 2020). The results of all coefficient estimates are presented in the Appendix.

\section{Results}

\section{Sample Description}

Table A2 in the Appendix presents the summary statistics for households in both the U.S. and Israeli survey samples. In general, the samples well-approximated the populations of their respective countries in terms of gender, age, income, and race/ethnicity in the US or religion/ethnicity in Israel, as compared to the 2019 American Community Survey by the U.S. Census Bureau (U.S. Census Bureau, 2021) or Israeli population data compiled from several sources (Central Bureau of Statistics, 2019; Feldman \& Heffetz, 2021; Organization for Economic Cooperation \& Development, 2015; World Bank, 2019). ${ }^{8}$ However, there are some key differences we highlight here. The U.S. survey sample is more educated than the U.S. population as a whole, as 58.4\% of the survey sample reported holding a bachelor's degree or higher while only $33.1 \%$ of the U.S. population had this level of educational attainment. Israeli respondents were somewhat more likely to identify as Jewish and less likely to identify as some other ethnicity/religion, somewhat less likely to identify as male, somewhat more likely to come from the Haifa region and less likely to come from the Tel Aviv region. Everyone in the Israeli sample is considered to have health insurance as they have a national public health insurance program, while $5.5 \%$ of the U.S. sample did not report any type of health insurance.

\section{Comparing Expenditure Changes During the Pandemic}

This section examines the extent to which respondents reported household expenditure changes for basic needs during the pandemic, comparing the shifts in these expenditures between U.S. and Israeli households. Table 1 presents the results of our analysis. In terms of housing payments, reported expenditures were very stable in both Israel and the US. Roughly $85-90 \%$ of respondents in both countries reported that their household expenditures had not changed, while 6-9\% reported that expenditures had increased and $6-7 \%$ reported that expenditures had decreased. Utility bill

\footnotetext{
${ }^{8}$ See Tables A8 and A9 in the Appendix for comparisons between our analytic sample and key population indicators for both countries.
}

Table 1 Household expenditure changes and material hardship experiences during the pandemic, by country

\begin{tabular}{|c|c|c|}
\hline & $\begin{array}{l}\text { US } \\
\%\end{array}$ & $\begin{array}{l}\text { Israel } \\
\%\end{array}$ \\
\hline \multicolumn{3}{|l|}{ Expenditure changes } \\
\hline \multicolumn{3}{|l|}{ Rent/mortgage $^{\mathrm{a}}$} \\
\hline Increased & $5.7 \%$ & $8.6 \%$ \\
\hline Not changed & $88.1 \%$ & $84.9 \%$ \\
\hline Decreased & $6.3 \%$ & $6.5 \%$ \\
\hline \multicolumn{3}{|l|}{ Utilities } \\
\hline Increased & $11.4 \%$ & $40.1 \%$ \\
\hline Not changed & $81.1 \%$ & $55.6 \%$ \\
\hline Decreased & $7.6 \%$ & $4.3 \%$ \\
\hline \multicolumn{3}{|l|}{ Food } \\
\hline Increased & $36.3 \%$ & $46.3 \%$ \\
\hline Not changed & $44.8 \%$ & $32.3 \%$ \\
\hline Decreased & $18.9 \%$ & $21.4 \%$ \\
\hline \multicolumn{3}{|l|}{ Credit card debt payments ${ }^{\mathrm{b}}$} \\
\hline Increased & $20.2 \%$ & $31.3 \%$ \\
\hline Not changed & $59.8 \%$ & $39.6 \%$ \\
\hline Decreased & $20.0 \%$ & $29.1 \%$ \\
\hline \multicolumn{3}{|l|}{ Material hardships } \\
\hline \multicolumn{3}{|l|}{ Rent/mortgage } \\
\hline Skipped rent/mortgage & $8.1 \%$ & $10.3 \%$ \\
\hline \multicolumn{3}{|l|}{ Utilities } \\
\hline Skipped utility bill & $11.2 \%$ & $17.8 \%$ \\
\hline \multicolumn{3}{|l|}{ Food } \\
\hline Food insecurity & $23.9 \%$ & $21.4 \%$ \\
\hline Observations & 4684 & 1889 \\
\hline
\end{tabular}

${ }^{\mathrm{a} O n l y}$ for those who pay rent or mortgage

${ }^{\mathrm{b}}$ Those who only have a credit card

payments, by contrast, were very stable in the US $(81 \%$ reporting no change) and relatively unstable in Israel (56\% reporting no change); a difference largely driven by higher proportions of Israelis reporting utility bill increases than Americans (40\% vs 11\%). Food expenditures and credit card payments were also relatively unstable in both countries, with majorities or near majorities reporting that their expenses in these categories had changed, and in both cases Israeli respondents were more likely to report household expense increases than those in the US.

\section{Comparing Hardship Experiences During the Pandemic}

In this section we address our second research question, concerning the experience of material hardships during the pandemic and how these experiences differed between the US and Israel. Table 1 shows that, in both the US and Israel, skipping housing payments was the least common material 
Table 2 Polychoric correlations of outcome variables, by country

Panel A: United States $(\mathrm{N}=4684)$

\begin{tabular}{|c|c|c|c|c|c|c|c|}
\hline Variables & (1) & (2) & (3) & (4) & $(5)$ & (6) & (7) \\
\hline \multicolumn{8}{|l|}{ Expenditure changes } \\
\hline (1) Rent/mortgage & 1.000 & & & & & & \\
\hline (2) Utilities & 0.295 & 1.000 & & & & & \\
\hline (3) Food & 0.206 & 0.359 & 1.000 & & & & \\
\hline (4) Credit card debt payments & 0.126 & 0.049 & 0.108 & 1.000 & & & \\
\hline \multicolumn{8}{|l|}{ Hardships } \\
\hline (5) Skipped rent/mortgage & -0.089 & -0.042 & 0.046 & -0.392 & 1.000 & & \\
\hline (6) Skipped bills & -0.056 & -0.065 & -0.025 & -0.339 & 0.771 & 1.000 & \\
\hline (7) Food insecurity & -0.110 & -0.049 & 0.027 & -0.363 & 0.647 & 0.735 & 1.000 \\
\hline \multicolumn{8}{|l|}{ Panel BL Israel ( $\mathrm{N}=1889)$} \\
\hline Variables & $(1)$ & (2) & (3) & (4) & $(5)$ & (6) & (7) \\
\hline \multicolumn{8}{|l|}{ Expenditure changes } \\
\hline (1) Rent/mortgage & 1.000 & & & & & & \\
\hline (2) Utilities & 0.295 & 1.000 & & & & & \\
\hline (3) Food & 0.366 & 0.560 & 1.000 & & & & \\
\hline (4) Credit card debt payments & 0.360 & 0.236 & 0.412 & 1.000 & & & \\
\hline \multicolumn{8}{|l|}{ Hardships } \\
\hline (5) Skipped rent/mortgage & -0.161 & 0.019 & -0.049 & -0.194 & 1.000 & & \\
\hline (6) Skipped bills & -0.178 & -0.197 & -0.134 & -0.255 & 0.772 & 1.000 & \\
\hline (7) Food Insecurity & -0.248 & -0.143 & 0.036 & -0.202 & 0.680 & 0.746 & 1.000 \\
\hline
\end{tabular}

hardship (8.1\% in the U.S. and $10.3 \%$ in Israel), followed by skipping utility bill payments $(11.2 \%$ in the US and $17.8 \%$ in Israel) and food insecurity (23.9\% in the US and $21.4 \%$ in Israel). Notably, the rate of skipped utility payments is roughly $60 \%$ higher in Israel than the US, while the rates of skipped housing payments and food insecurity are similar between the two countries.

\section{Examining the Relationships Between Expenditures and Hardships}

Table 2 examines the polychoric correlations (Olsson, 1979) between these outcome measures in the US (Panel A) and Israel (Panel B). Overall, we find that a given expenditure change tends to positively correlate with other expenditure changes and a given hardship tends to positively correlate with other hardships, but that hardships and expenditure changes are negatively correlated. This pattern indicates that households in both countries do not appear to be substituting one expense for another. For example, they do not appear to substituting housing or utility payments for food payments, on average, nor do they appear to be skipping one type of expense to cover another type of expense. An interesting exception to this in both countries is the relationship between food expenditures and food insecurity, as food expenditures have a very slight positive correlation with food insecurity. This stands in contrast to the negative correlations between housing expenditures and skipped housing payments, or utility expenditures and skipped bills, potentially indicating that food insecurity in both countries stems in part from increasing food expenses during the pandemic (e.g., parents needing to provide more food while their children are at home).

\section{The Relationship Between Expenditure Changes, Hardships, and Household Characteristics in the U.S. and Israel}

In this section, we explore our final research question concerning the relationship between household characteristics, expenditure changes, and hardship. Figures 1, 2, 3 and 4 present the results of multinomial logistic regression analyses estimating the relationship between household characteristics and expenditure changes during the pandemic, while Figs. 5, 6 and 7 present the results of binary logistic regression models estimating the relationship between household characteristics and the experience of hardship during the pandemic. In each set of results, we present coefficient plots for key household characteristics including race/ethnicity or religion/ethnicity, pre-pandemic household income, and employment, though we also control for other household characteristics as described above and in Table A1. 


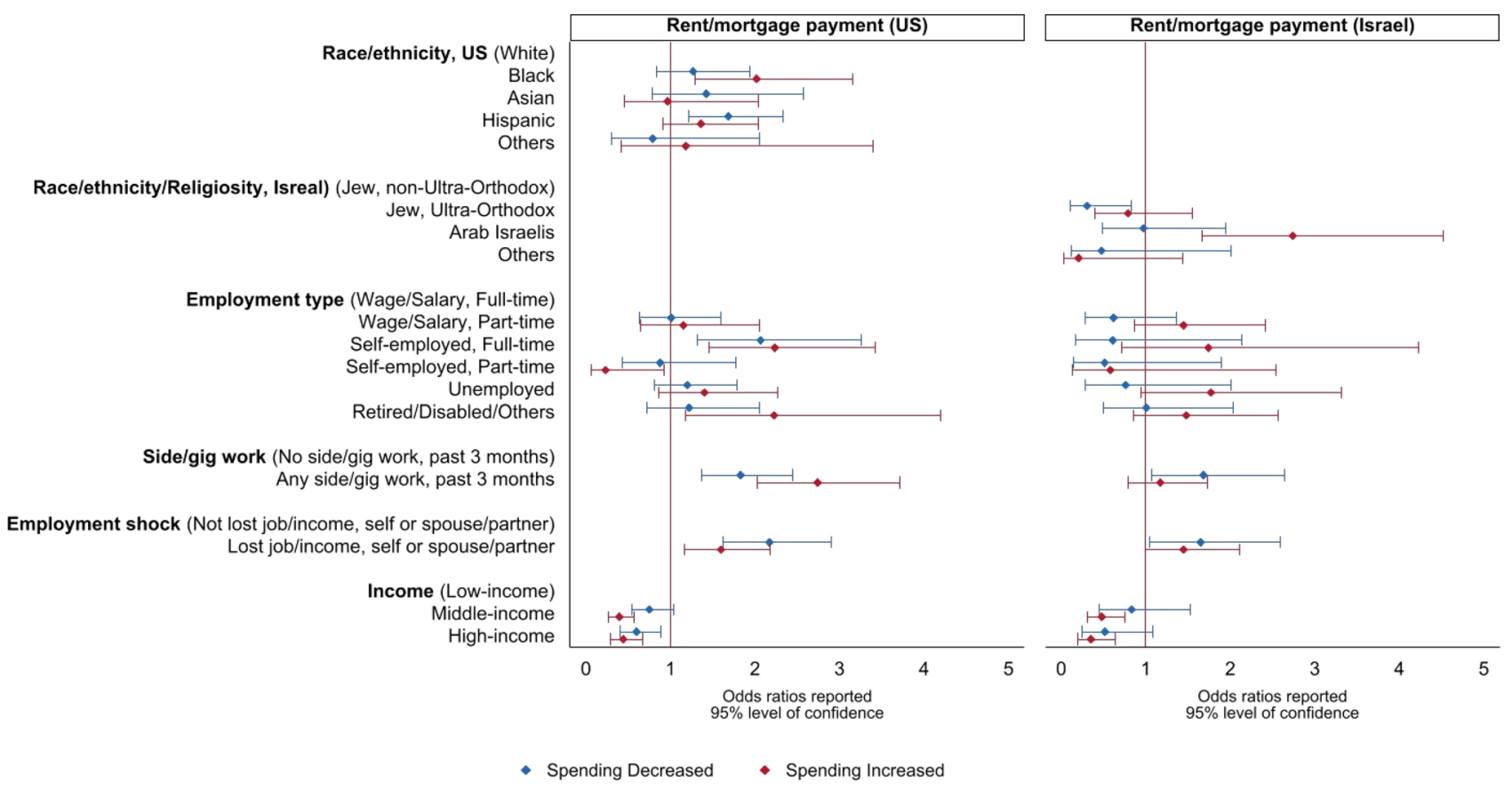

Fig. 1 Housing expenditures during COVID-19, by country. This figure presents the results of two multinomial logistic regressions estimating the relationship between race/ethnicity (or religion/ethnicity), employment, and income indicators on changes in rent/mortgage spending in the US and Israel. The reference spending category is no change in spending. The reference categories for the independent variables are in parentheses. Models also control for an array of other demographic and financial indicators, outlined in Table A1 in the Appendix. $\mathrm{N}(\mathrm{US})=3789$. $\mathrm{N}($ Israel $)=1396$

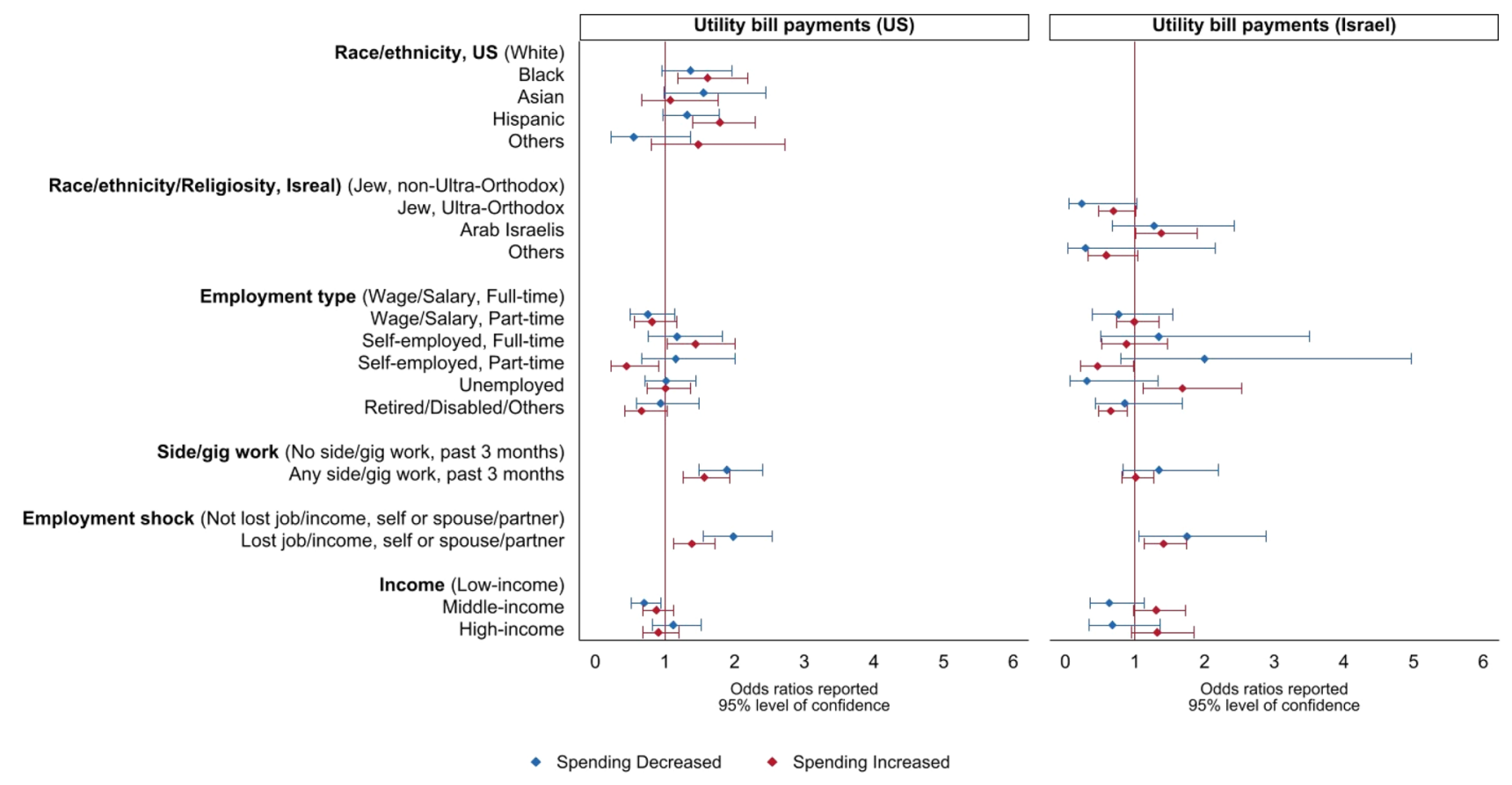

Fig. 2 Utility bill expenditures during COVID-19, by country. This figure presents the results of two multinomial logistic regressions estimating the relationship between race/ethnicity, employment, and income indicators on changes in utility spending in the US and Israel. The reference spending category is no change in spending. The ref- erence categories for the independent variables are in parentheses. Models also control for an array of other demographic and financial indicators, outlined in Table A1 in the Appendix. N(U.S.) $=4592$. $\mathrm{N}($ Israel $)=1858$ 


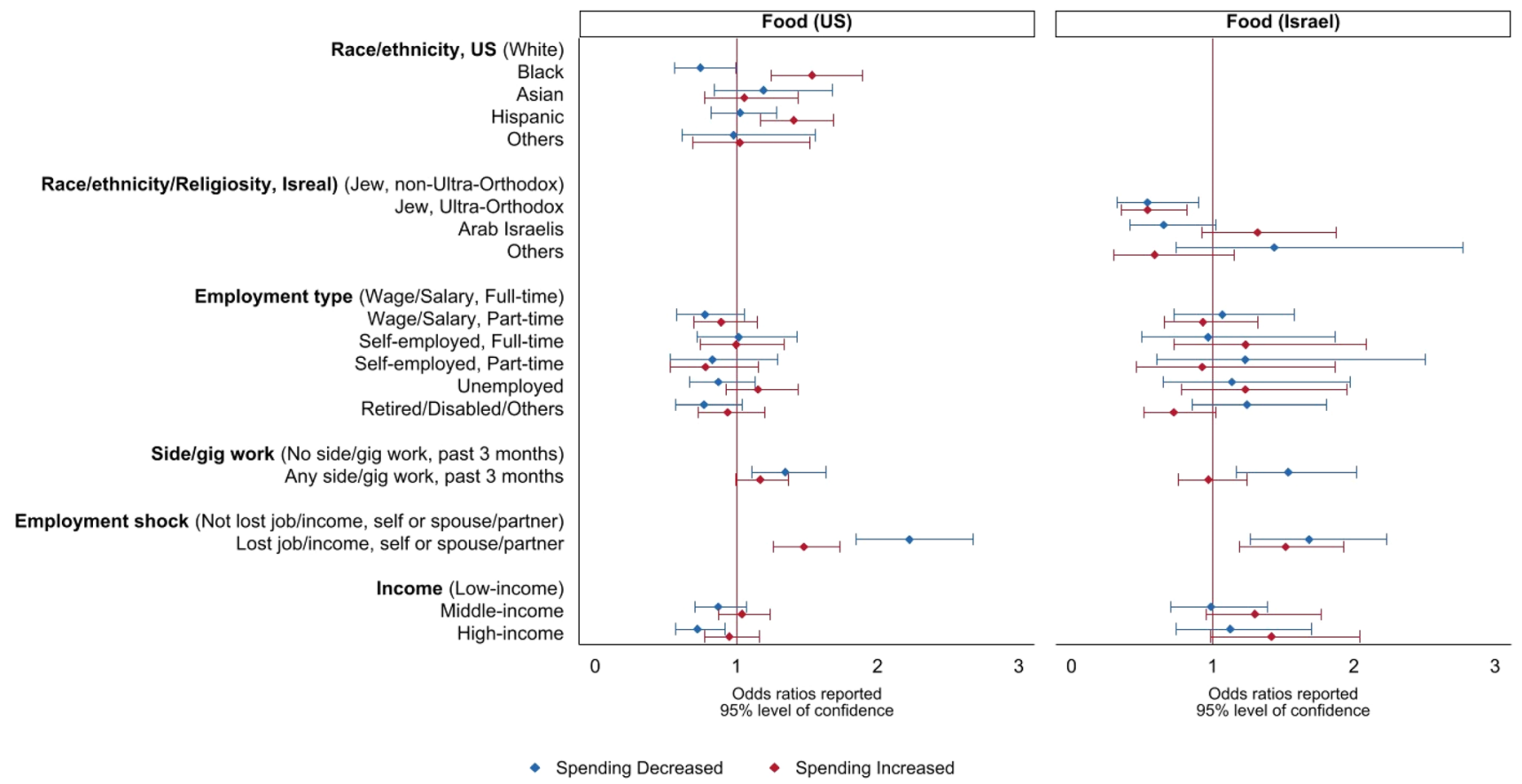

Fig. 3 Food expenditures during COVID-19, by country. This figure presents the results of two multinomial logistic regressions estimating the relationship between race/ethnicity, employment, and income indicators on changes in food spending in the US and Israel. The reference spending category is no change in spending. The ref- erence categories for the independent variables are in parentheses. Models also control for an array of other demographic and financial indicators, outlined in Table A1 in the appendix. $\mathrm{N}(\mathrm{US})=4615$. $\mathrm{N}($ Israel $)=1858$

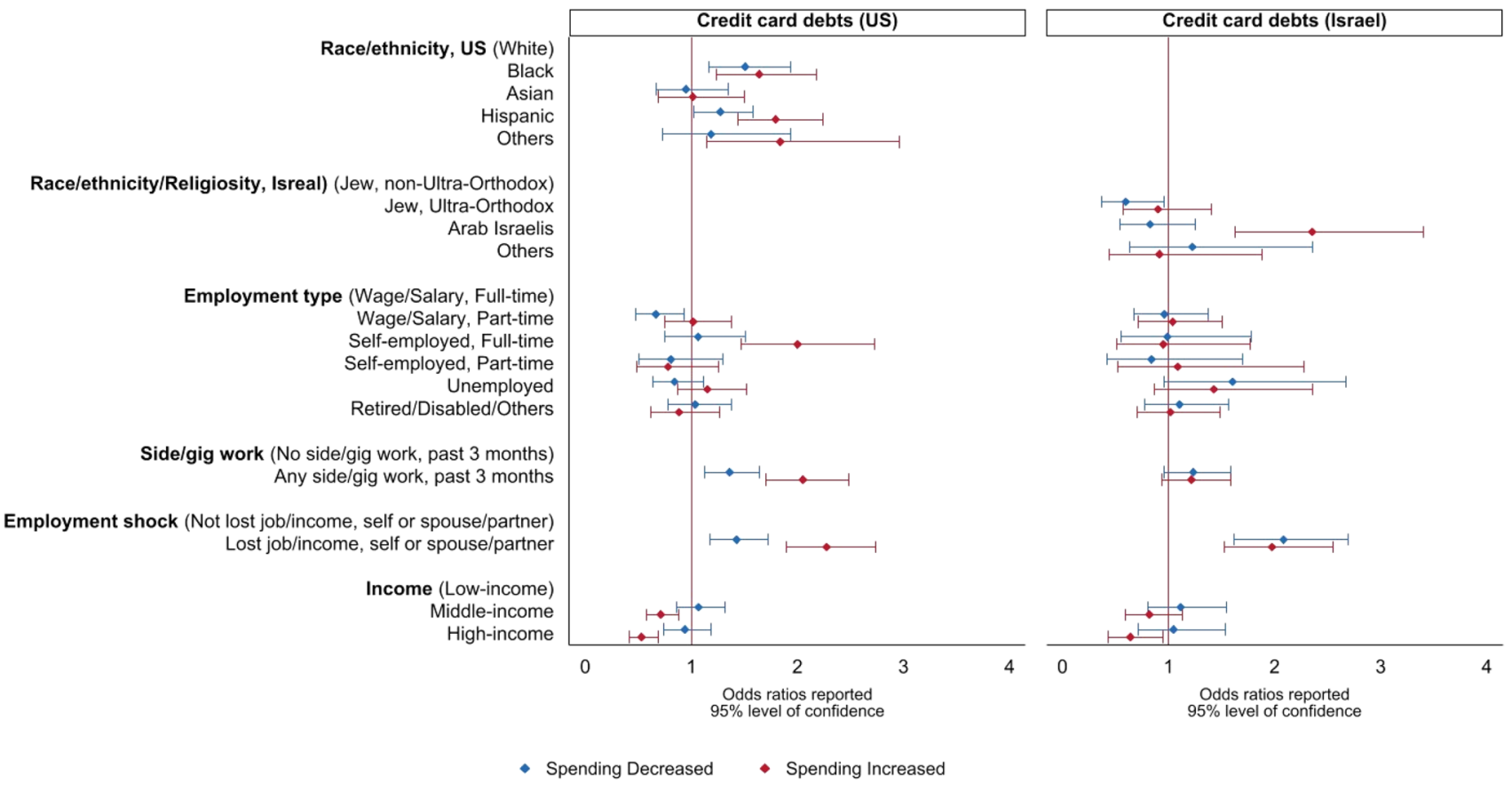

Fig. 4 Credit card debts during COVID-19, by country. This figure presents the results of two multinomial logistic regressions estimating the relationship between race/ethnicity, employment, and income indicators on changes in credit card debt in the US and Israel. The reference spending category is no change in spending. The refer- ence categories for the independent variables are in parentheses. Models also control for an array of other demographic and financial indicators, outlined in Table A1 in the Appendix. $\mathrm{N}(\mathrm{US})=4236$. $\mathrm{N}($ Israel $)=1787$ 


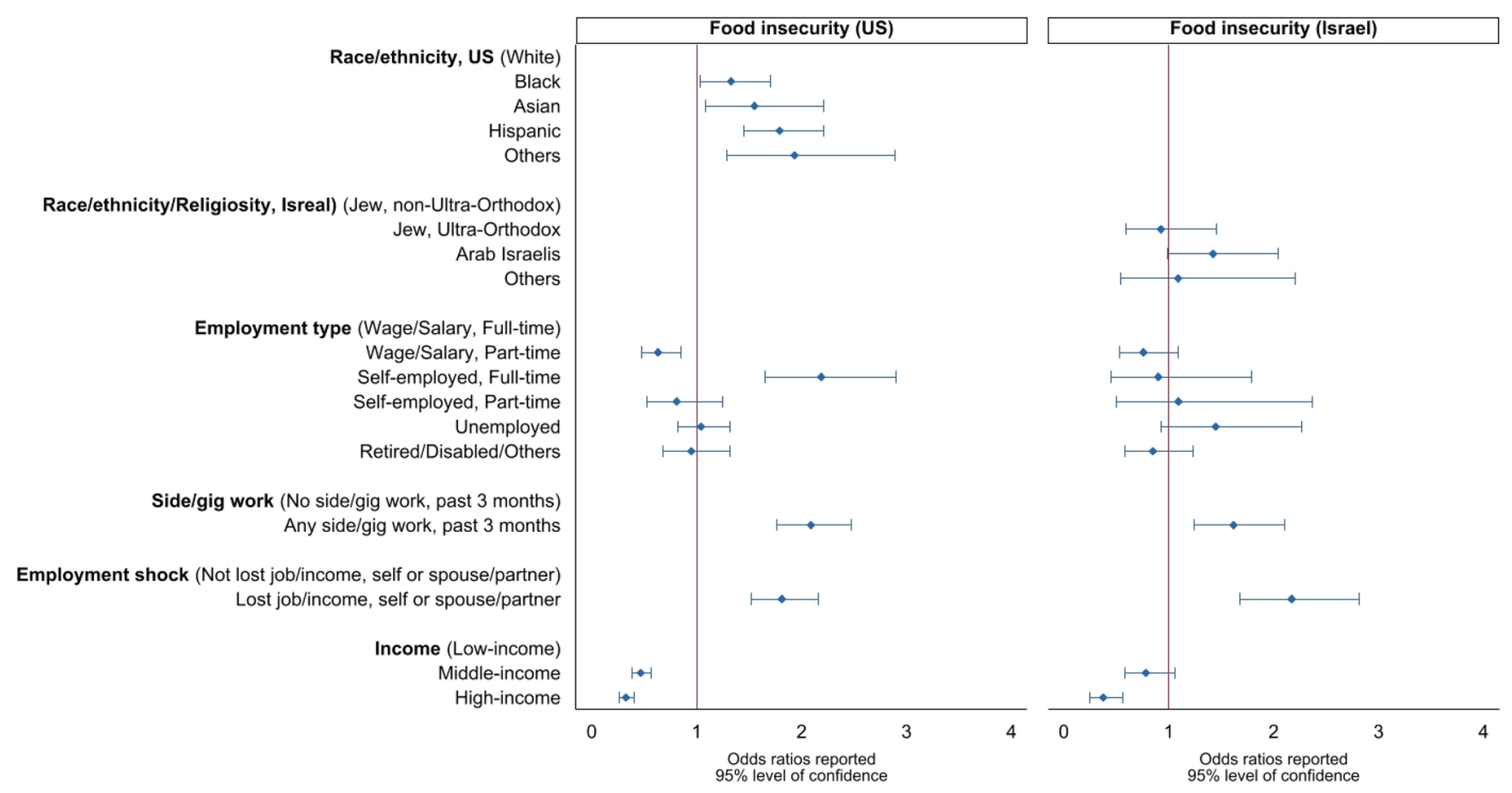

Fig. 5 Food insecurity during COVID-19, by country. This figure presents the results of two binary logistic regressions estimating the relationship between race/ethnicity, employment, and income indicators on food insecurity in the US and Israel. The reference categories for the independent variables are in parentheses. Models also control for an array of other demographic and financial indicators, outlined in Table A1 in the Appendix. N(US) $=4684 . \mathrm{N}($ Israel $)=1889$

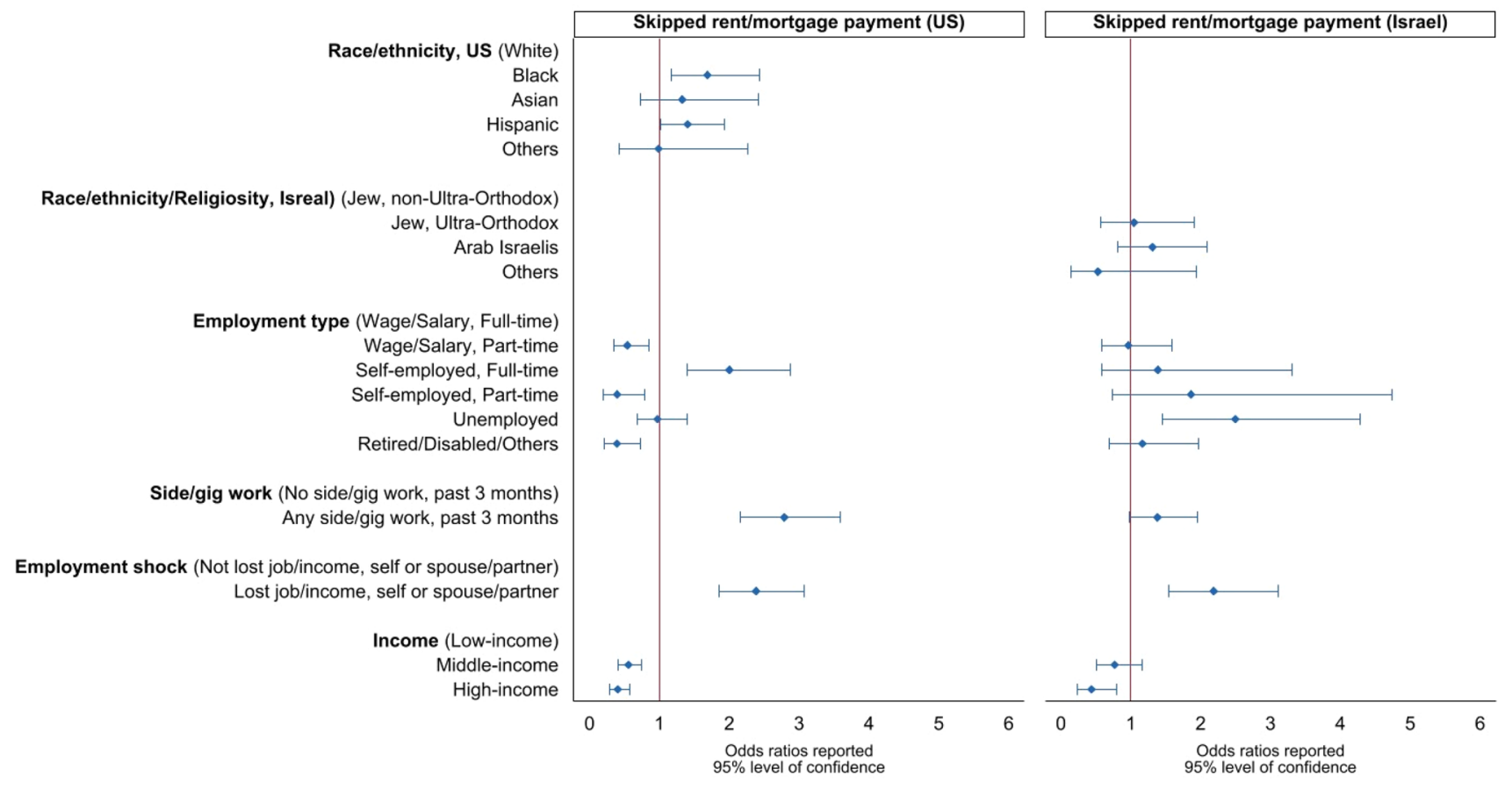

Fig. 6 Skipped housing payments during COVID-19, by country. This figure presents the results of two binary logistic regressions estimating the relationship between race/ethnicity, employment, and income indicators on skipped housing payments in the US and
Israel. The reference categories for the independent variables are in parentheses. Models also control for an array of other demographic and financial indicators, outlined in Table A1 in the Appendix. $\mathrm{N}(\mathrm{US})=4684 . \mathrm{N}($ Israel $)=1889$ 


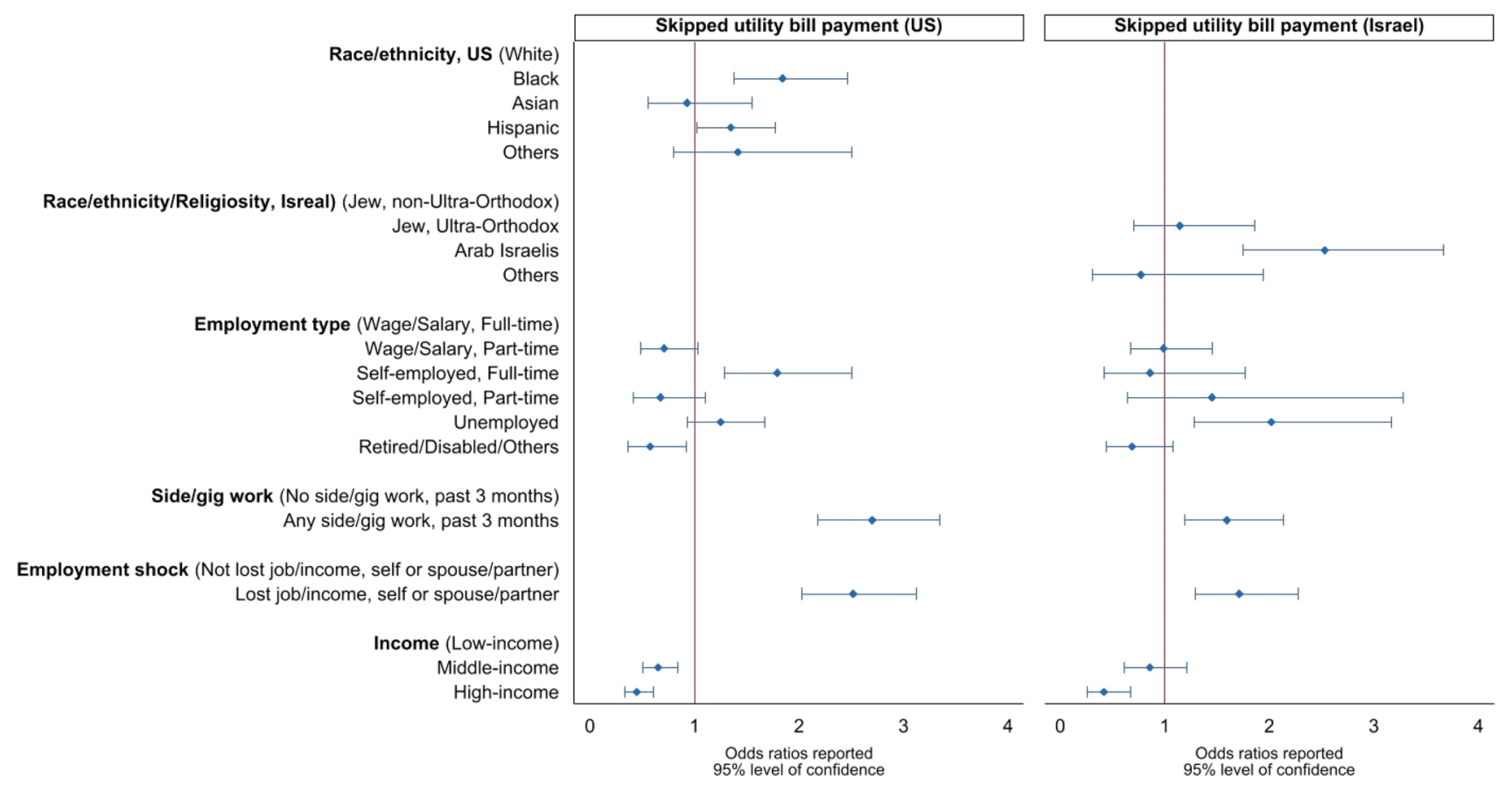

Fig. 7 Skipped bill payments during COVID-19, by country. This figure presents the results of two binary logistic regressions estimating the relationship between race/ethnicity, employment, and income indicators on skipped utility bill payments in the US and Israel. The

We begin by examining the predictors of changes in housing expenditures in Fig. 1. Racial/ethnic and religious/ethnic minorities in both countries were more likely to report spending shifts on housing payments. Relative to White respondents, Black respondents in the US were more likely to report spending increases on housing payments and Hispanic respondents were more likely to report spending decreases. In Israel, Arab Israeli respondents were much more likely to report increased spending on housing relative to non-Ultra-Orthodox Jews. Full-time self-employed respondents in the US reported substantial changes in their housing expenditures, as did respondents who were out of the labor market (e.g., retired or disabled); these patterns were not observed in Israel. Gig/side job workers in the US were much more likely to report increased and decreased housing expenditures, while Israeli gig/side job workers were directionally more likely to report spending decreases. Similarly, households with COVID-19-related job or income losses in both the US and Israel were more likely to report housing expenditure increases and decreases, though the estimates for Israelis are imprecise. Relative to low-income households, middle- and high-income households in the US and Israel were less likely to report housing expenditure increases and, in the US, high-income households were somewhat less likely to report expenditure decreases. reference categories for the independent variables are in parentheses. Models also control for an array of other demographic and financial indicators, outlined in Table A1 in the Appendix. $\mathrm{N}(\mathrm{US})=4864$. $\mathrm{N}($ Israel $)=1889$

Turning to utility payment expenditure changes in Fig. 2, we see that Black and Hispanic respondents in the US also reported utility bill expenditure increases, though minority respondents in Israel did not. In general, employment status was not correlated with utility bill expenditure changes in either country. Similar to the pattern in housing payments, workers with gig or side employment and those reporting lost jobs/incomes due to COVID-19 in the US were more likely to report both increases and decreases in utility bill payments. In Israel, this was only true for those who had COVID-19-related job/income loss. Unlike the pattern in housing payment expenditures, the relationships between income and utility payment expenditure shifts were relatively weak.

In Fig. 3, we examine shifts in food expenditures. Black and Hispanic respondents in the US were more likely to report increased food expenditures, while Ultra-Orthodox Jews in Israel were more likely to report no change in expenditures. Respondents in both countries who lost a job/income due to COVID-19 were more likely to report both increased and decreased expenditures on food, while workers with gig or side jobs in both countries were more likely to report spending decreases on food. The relationship between employment and income variables and food expenditures in both countries was relatively weak. 
The final expenditure category we examine concerns credit card debt, shown in Fig. 4. Black, Hispanic, and Other race/ethnicity respondents in the US were more likely to report increased credit card debt, with Black respondents also more likely to report credit card debt decreases. In Israel, Arab Israeli respondents were much more likely to report credit card debt increases, while Ultra-Orthodox Jews were less likely to report debt decreases. Relative to full-time wage/salary employees, full-time self-employed respondents in the US were much more likely to report increased credit card debt, while part-time wage/salary workers were less likely to report decreases in credit card debt. In Israel, employment status was not significantly related to changes in credit card debt. Similar to other spending outcomes, households in both countries with gig or side jobs and those who lost a job or income due to COVID-19 report high levels of volatility in their credit card debt amounts, though the estimates on gig/side jobs in Israel are imprecise.

Finally, in Figs. 5, 6 and 7 we examine the relationship between household characteristics and the experience of hardship in the two countries. Generally speaking, the relationships between household characteristics and hardshipswhich include food insecurity, skipped housing payments, and skipped utility payments-appear much stronger in the US than in Israel. Black respondents in the US were more likely to report all measured hardships relative to White respondents, while Hispanic and Other race respondents were more likely to report food insecurity. In Israel, only Arab Israelis were more likely to report hardships, relative to non-Ultra-Orthodox Jews. Relative to full-time wage/salary employees, self-employed respondents in the US were much more likely to report all measured hardships, while part-time workers (both self-employed and wage/salary employees) appeared to be at less risk of many hardships. In Israel, the relationship between employment status and hardship was much weaker, though respondents who were unemployed prior to the pandemic were more likely to experience all measured hardships. In both countries, reporting gig or side work in the household was associated with increases in all hardships, though hardship coefficients in the US were higher than those in Israel. The association between COVID19-related job or income loss and all modeled hardships was significant (and similar) in both countries. In the US, both middle- and high-income households were less likely to report all hardships than low-income households, while in Israel the experience of low- and middle-income households was similar.

While the outcomes used in this analysis capture hardships that occurred during the early phase of the pandemic, they are not necessarily hardships that occurred because of the pandemic. For example, an individual may have skipped their utility payments because they had medical expenses from a non-COVID-19 illness, or because they had an expensive car repair. As a supplemental analysis, we re-estimated our hardship models using measures that specifically ask if a given hardship was due to financial issues caused by the COVID-19 pandemic (see Table A1 in the Appendix). In every case, the majority of households experiencing a given hardship attributed that hardship to the COVID-19 pandemic and, as shown in Figures A1-A3 in the Appendix, models using these COVID-19-specific hardships produced very similar estimates to those using the more general hardship measures.

\section{Discussion}

This study examined the self-reported spending behaviors and hardships of households during the COVID-19 pandemic in the US and Israel, and how these outcomes intersected with measures of employment, income, and race/ethnicity/religion. Using two similar national surveys that used similar surveying and sampling methods and were administered across similar time periods, we found that self-reported spending on housing was mostly stable, with around $85 \%$ of respondents in both countries reporting unchanged housing expenditures. However, spending on food and credit card debts was more volatile. For example, $36 \%$ of U.S. respondents and $46 \%$ of Israeli respondents reported increased food expenditures, and a respective $20 \%$ and $31 \%$ reported increased credit card debt. While utility payments were roughly stable in the US, Israeli households were almost four times as likely to report utility payment increases as U.S. households. Hardship was common during the early months of the pandemic and, while rates of skipping housing payments or food insecurity were similar between the two countries, the rate of skipped utility bills in Israel was almost $60 \%$ higher than in the US.

Though volatility and hardship were common in both countries, early research indicates that the impacts of the pandemic were felt disproportionately by low-income and racial/ethnic or religious/ethnic minority households, as well as households with precarious work arrangements (Despard et al., 2020; Hardy \& Logan, 2020; Tomer \& Kane, 2020). Our analysis validates and extends these early findings. Racial/ethnic/religious minorities in both countries (Black and Hispanic respondents in the US and Ultra-Orthodox Jewish and Arab respondents in Israel) were more likely than White and non-Ultra-Orthodox Jewish respondents in the US and Israel, respectively, to report spending changes in a variety of categories. Black and Hispanic respondents in the US were also more likely to report experiencing hardships during the pandemic, though only Arab respondents in Israel appeared at increased risk of hardship.

Pre-pandemic employment and income indicators, by contrast, appeared more predictive of spending volatility and 
hardship outcomes in the US than in Israel. As some examples of this dynamic, full-time self-employed respondents and those reporting gig or side work in the US were significantly more likely to experience volatility in almost every category and every modeled hardship, while these relationships were much weaker in Israel; part-time employees in the US appeared less vulnerable to hardship; and being unemployed pre-COVID was much more predictive of hardship in Israel than in the US. Additionally, low-income households in both countries were more vulnerable to spending shifts and hardship than high-income households, but middle-income households in the US also appeared more vulnerable than their Israeli counterparts.

Some degree of expenditure volatility is to be expected during a period in which both countries' unemployment rates spiked. Indeed, we observed that changes in expenditures were positively correlated with each other, as were different hardships, which is consistent with an interpretation that shifts in household consumption behavior were driven by broad shifts in their economic circumstances rather than by households substituting one category of expenses for another. Despite this, we still observed significant expenditure volatility for households even after controlling for COVID-19-related job/income loss and pre-pandemic employment status, which reflect exposure to the economic effects of the pandemic. Prior theoretical and empirical work provides potential explanations for these patterns. High expenditure volatility, particularly in terms of increased food expenditures, may reflect households' desire to satisfy their fundamental needs while also potentially showing patterns of panic-buying, which is associated with stress, fear of the unknown (Yuen et al., 2020), and anxiety (Tsao et al., 2019), especially among vulnerable social groups and during times of crisis (Loxton et al., 2020).

Drawing upon psychological reactance and Hierarchy of Needs theories, the increase and decrease in households' spending may also be explained by frequently changing needs (or the changing perception of needs) during the early stages of the pandemic. Households likely adapted their patterns of spending in response to the disruption caused by the pandemic (Clee \& Wicklund, 1980). This disruption and the associated stress may have pushed households to prioritize their spending on basic needs in order to buffer themselves against the threat of the pandemic. These changes may have been individually rational, such as increasing food expenditures in response to continual lockdown or supply shortages, but they may also serve as psychological coping behaviors in the face of the uncertainty created by the pandemic (Arafat et al., 2020). In the case of vulnerable populations, such as racial/ethnic/religious minorities and households with low incomes, high volatility of consumption of non-durable necessities may reflect their focus on juggling expenditures on an array of basic needs in the face of increased financial constraints and economic uncertainty. Indeed, prior empirical work on the Great Recession shows that households with large debt burdens or minimal wealth to draw on were more likely to experience spending volatility (Dynan \& Edelberg, 2013; Dynan et al., 2012; Krueger et al., 2016; Mian et al., 2013). Given this, it is perhaps unsurprising that the minority and low-income groups in our study, who often have relatively high debt burdens and low assets (Bhutta et al., 2020; Employer Benefits Research Institute, 2021), experienced higher degrees of expenditure volatility.

Many of the dynamics in expenditures and hardships observed in both countries are also likely attributable to the rapidly changing policy and economic environments of both countries during the pandemic. A precise accounting of the influence these factors had in driving these differences is beyond the scope of this paper. Israel and the US had different social safety net arrangements prior to the pandemic, different policy responses to the pandemic, and different experiences with the virus itself. For example, our study found that $36 \%$ of U.S. respondents reported increased food expenditures relative to 3 months prior while only $19 \%$ reported decreased food expenditures, yet we also observed that $24 \%$ of U.S. households reported food insecurity. There are an array of policy-related factors that may be driving this pattern. For example, the Families First Coronavirus Response Act increased eligibility and funding for the Supplemental Nutrition Assistance Program (SNAP) and created a new program (Pandemic-EBT) that aimed to help parents pay for children's meals that might otherwise be provided for free by schools (Center on Budget \& Policy Priorities, 2021). These policies may have had the effect of boosting food expenditures for the most economically vulnerable (indeed, Fig. 3 shows that losing income due to COVID-19 is the single largest predictor of increased food expenditures), yet may have been insufficient to reduce the risk of food insecurity in these households (COVID-19-related income loss was also among the largest predictors of food insecurity).

The effects of U.S. federal and state policies on the housing and utility expenditure and hardship dynamics we observe in this study are also ambiguous. Though U.S. households facing a lost job or income due to COVID-19 were more likely to report volatility in their housing/utility expenditures and skipped housing/bill payments, policy actions that imposed eviction and utility shutoff moratoria may have changed how households prioritize these expenditures. If cash-strapped individuals faced a lower likelihood of eviction or having their power shut off during the pandemic, they may have chosen to prioritize expenses that put food on their table rather than expenses that kept them current on their bills.

Similarly, in Israel, a range of factors could explain our findings. We observed that a high proportion of Israeli respondents reported increases in their food and utility 
expenditures relative to the prior 3 months ( $46 \%$ and $40 \%$, respectively), while at the same time, $21 \%$ of respondents reported food insecurity and $18 \%$ said they skipped a bill payment within the past 3 months. We cannot directly attribute these results to the receipt of various government supports. However, it is highly likely that, given the reported increases in food and utility expenditures, the increase in household hardship may have been much greater in the absence of rigorous and timely pandemic-related financial assistance to a wide range of households. With respect to housing hardship, it is perhaps not surprising that a combination of factors-including unchanged housing expenditures for $85 \%$ of respondents, financial (e.g., unemployment benefits) and non-financial (e.g., deferment on loan payments) assistance, and the severity of consequences of late housing payments-determined that it was the least experienced household hardship. At the same time, considering that the most socially and economically vulnerable households, such as Arab Israelis and households experiencing job losses, tended to experience higher rates of material hardship, the government support provided during and beyond the pandemic may not have been enough to ensure the financial stability of more vulnerable households. Considering that economically and socially disadvantaged households fared worse before the pandemic and may have been affected by the pandemic to the greater extent, more equitable policies may be needed to address the differences in hardship experiences in Israel.

Each of these factors, in addition to other macroeconomic and socio-economic differences between the countries, may be contributing to the differences in spending behaviors and hardships we observe in this study. Yet despite these differences, we found that both countries were somewhat unable to insulate financially vulnerable or economically marginalized groups from disproportionately experiencing hardships and spending volatility during the pandemic. Similarly, policies enacted prior to and during the pandemic seem insufficient to insulate certain types of workers from the economic effects of the pandemic, including gig/side job workers or those who experienced COVID-19-related job/income loss.

Some of these disparities are almost certainly due to preexisting differences in the economic security of these populations. Black and Hispanic respondents in the US, as well as Arab Israeli and Ultra-Orthodox Jews in Israel, face a combination of high poverty rates and low wealth that likely left them vulnerable to the economic effects of the pandemic. The large hardship increases we observed among certain types of workers also indicates that the large economic relief packages in both countries were insufficient. This may be due to issues concerning the overall scope of the relief packages, such as the fact that the CARES Act stimulus payments in the US excluded certain individuals (e.g., adult dependents), or issues concerning the implementation of the programs, such as large and well-documented delays in U.S. households accessing unemployment benefits (Roll \& Grinstein-Weiss, 2020).

There are several limitations to this study. Foremost, this study is descriptive in nature and does not explore the causal impacts of the COVID-19 pandemic on household spending and hardship experiences. Similarly, this study does not examine what specific policy remedies led to different outcomes in the US and Israel-a subject future research should address. Another limitation is that, while targeted sampling ensures that the characteristics of our samples reflect the US and Israeli adult populations, online surveys impose technology requirements that may exclude certain segments of the population, thus limiting external validity. Though our sample was constructed to be reflective of the U.S. and Israeli respondents on key financial and demographic characteristics, we do see some differences between our samples and their respective populations- the U.S. sample was more educated than the U.S. population as a whole, while the Israeli sample had a somewhat different ethnic/ religious identification and geographical dispersion as the Israeli population. These differences may limit our ability to generalize these findings, even as we control for an array of factors in our multiple regression models. Additionally, all the variables used in this study come from self-reported survey responses to questions that ask respondents to recall specifics about their spending and economic circumstances (e.g., skipping a bill in the last 3 months, or how their spending now compares to 3 months prior). While the timeframe covered through these questions is only 3 months, it is possible that answers to these questions suffer from imperfect recall. Finally, our ability to compare the experience of these two countries is limited by the sample size differences of the two surveys, as the U.S. sample has substantially more respondents than the Israeli sample. While this difference is understandable given the overall population differences of the countries, some differences (or similarities) observed in this study may be a function of the different levels of precision in our estimates for the two countries.

Future research in this area should continue to build evidence around the differential consumer experience of COVID-19 across different countries. The COVID-19 pandemic has resulted in countries engaging in a diverse and largely unprecedented array of policy innovations to manage both the public health and economic impacts of the pandemic, and once the pandemic has subsided there will be a unique opportunity for countries to learn from each other in preparation for the next crisis. In particular, research should identify how different key groups within populations in different countries (e.g., women, households with low incomes and/or low educational attainment, etc.) recovered or stagnated following the economic impacts of the pandemic. Comparative work is essential to facilitating this learning, 
and our work represents a first step toward building this knowledge base in the context of COVID-19.

Supplementary Information The online version contains supplementary material available at https://doi.org/10.1007/s10834-021-09814-z.

Funding No funding directly supported the research in this manuscript. However, the collection of the data used in this manuscript was funded by the JPMorgan Chase Foundation (Grant \#: 63241517).

Data Availability To access the data or code used to generate the analyses in this study, please contact Stephen Roll at stephen.roll@wustl. edu.

\section{Declarations}

Conflict of interest The authors declare they have no conflicts of interest.

Ethical Approval All procedures performed in studies involving human participants were in accordance with the ethical standards of the institutional review board of Washington University in St. Louis (IRB ID: 202004100) and with the 1964 Helsinki declaration and its later amendments or comparable ethical standards.

Informed Consent Informed consent was obtained from all individual participants included in the study.

\section{References}

Abbi, S. (2012). A need for product innovations to help LMI consumers manage financial emergencies. Doorways to Dreams Fund.

American Association for Public Opinion Research. (2016). Standard definitions final dispositions of case codes and outcome rates for surveys. American Association for Public Opinion Research.

Arafat, S. M. Y., Kar, S. K., Menon, V., Kaliamoorthy, C., Mukherjee, S., Alradie-Mohamed, A., Sharma, P., Marthoenis, M., \& Kabir, R. (2020). Panic buying: An insight from the content analysis of media reports during COVID-19 pandemic. Neurology, Psychiatry and Brain Research, 37, 100-103. https://doi.org/10.1016/J. NPBR.2020.07.002

Bachman, D., Barua, A., \& Gunnion, L. (2020). COVID-19 to impact consumer spending till vaccine is deployed. Deloitte Insights.

Bartfeld, J., \& Collins, J. M. (2017). Food insecurity, financial shocks, and financial coping strategies among households with elementary school children in Wisconsin. Journal of Consumer Affairs, 51(3), 519-548. https://doi.org/10.1111/joca.12162

Bhutta, N., Chang, A. C., Dettling, L. J., \& Hsu, J. W. (2020). Disparities in wealth by race and ethnicity in the 2019 survey of consumer finances. FEDS Notes. https://doi.org/10.17016/2380-7172.2797

Brinca, P., Duarte, J. B., \& Faria-e-Castro, M. F. (2020). Is the COVID19 pandemic a supply or a demand shock? Economic Synopses, 31, 13. https://doi.org/10.20955/es.2020.31

Bufe, S., Roll, S., Kondratjeva, O., Skees, S., \& Grinstein-Weiss, M. (2021). Financial shocks and financial well-being: What builds resiliency in lower-income households? Social Indicators Research, 1-29.

Center on Budget and Policy Priorities. (2021). States are using much-needed temporary flexibility in SNAP to respond to COVID-19 challenges. Center on budget and policy priorities. Retrieved from https://www.cbpp.org/research/food-assistance/ states-are-using-much-needed-temporary-flexibility-in-snap-torespond-to.

Central Bureau of Statistics. (2019). Statistical abstract of Israel 2019-no. 70. Retrieved from https://www.cbs.gov.il/en/publicatio ns/Pages/2019/Statistical-Abstract-of-Israel-2019-No-70.aspx.

Central Bureau of Statistics. (2020a). Labour force survey data.

Central Bureau of Statistics. (2020b). National accounts—gross domestic product.

Central Bureau of Statistics. (2020c). Social and economic consequences of the corona virus outbreak-interim summary (part 2). Retrieved from: https://www.cbs.gov.il/he/mediarelease/DocLib/ 2020/297/19_20_297e.pdf

Chase, S., Gjertson, L., \& Collins, J. M. (2011). Coming up with cash in a pinch: Emergency savings and its alternatives. http:// citeseerx.ist.psu.edu/viewdoc/summary?doi=10.1.1.369.4498.

Chun, Y., Roll, S., Miller, S., Larimore, S., Lee, H., \& GrinsteinWeiss, M. (2020). Racial and ethnic disparities in housing instability during the COVID-19 pandemic: The role of assets and income shocks. SSRN Electronic Journal. https://doi.org/ 10.2139/ssrn.3742097

Clee, M. A., \& Wicklund, R. A. (1980). Consumer behavior and psychological reactance. Journal of Consumer Research, 6(4), 389-405. https://doi.org/10.1086/208782

Coleman-Jensen, A. (2012). Predictors of U.S. food insecurity across nonmetropolitan, suburban, and principal city residence during the great recession. Journal of Poverty, 16(4), 392-411. https:// doi.org/10.1080/10875549.2012.720657

Collins, J. M., \& Gjertson, L. (2013). Emergency savings for lowincome consumers. Focus, 30(1), 12-17.

Congressional Research Service. (2021). Federal eviction moratoriums in response to the COVID-19 pandemic. Retrieved from https://crsreports.congress.gov/product/pdf/IN/IN11516.

Desmond, M., \& Kimbro, R. T. (2015). Eviction's fallout: Housing, hardship, and health. Social Forces, 94(1), 295-324. https://doi. org/10.1093/sf/sov044

Despard, M. R., Grinstein-Weiss, M., Chun, Y., \& Roll, S. (2020). COVID-19 job and income loss leading to more hunger and financial hardship. Washington, DC: Brookings Institution. Retrieved from https://www.brookings.edu/blog/up-front/2020/ 07/13/covid-19-job-and-income-loss-leading-to-more-hungerand-financial-hardship/.

Despard, M. R., Guo, S., Grinstein-Weiss, M., Russell, B., Oliphant, J. E., \& deRuyter, A. (2018). The mediating role of assets in explaining hardship risk among households experiencing financial shocks. Social Work Research, 42(3), 147-158.

Dovrat-Meseritz, A. (2020). Israeli consumers kept spending heavily throughout coronavirus upheaval, figures reveal. Haaretz. Retrieved from: https://www.haaretz.com/israel-news/business/ economy-finance/.premium-israeli-consumers-kept-spendingheavily-throughout-pandemic-figures-reveal-1.9355347

Dun \& Bradstreet. (2020). The impact of the coronavirus crisis on the economy a special analysis.

Dunn, A., Hood, K., \& Driessen, A. (2020). Measuring the effects of the COVID-19 pandemic on consumer spending using card transaction data (no. WP2020-5; BEA working paper series).

Dynan, K., \& Edelberg, W. (2013). The relationship between leverage and household spending behavior: Evidence from the 20072009 survey of consumer finances. Federal Reserve Bank of St. Louis Review, 95(5), 425-448.

Dynan, K., Mian, A., \& Pence, K. M. (2012). Is a household debt overhang holding back consumption? Brookings Papers on Economic Activity, Spring, 2012, 299-362.

Egger, D., Miguel, E., Warren, S. S., Shenoy, A., Collins, E., Karlan, D., Parkerson, D., Mobarak, A. M., Fink, G., Udry, C., Walker, M., Haushofer, J., Larreboure, M., Athey, S., LopezPena, P., Benhachmi, S., Humphreys, M., Lowe, L., Meriggi, N. 
F., Wabwire, A., Davis, C. A., Pape, U. J., Graff, T., Voors, M., Nekesa, C., Vernot, C. (2021). Falling living standards during the COVID-19 crisis: Quantitative evidence from nine developing countries. Science Advances, 7(6), eabe0997. https://doi.org/ 10.1126/sciadv.abe0997

Employer Benefits Research Institute. (2021). How is debt different by race and ethnicity? Fast Facts. https://www.ebri.org/docs/defau 1t-source/fast-facts/ff-375-debtbyrace-7jan21.pdf?sfvrsn=39bf3 a2f_4\#: :text=Race\%2FEthnicityandtheSCF\&text=Justoverth ree-quarters(77.7, withotherheadsdidso.

Farrell, D., \& Greig, F. (2017). Coping with costs: Big data on expense volatility and medical payments. Retrieved from www.jpmchasein stitute.com.

Federal Reserve Bank of St. Louis. (2021). Timeline of events related to the COVID-19 pandemic. Federal Reserve Bank of St. Louis.

Feldman, N., \& Heffetz, O. (2021). A grant to every citizen: Survey evidence of the impact of a direct government payment in Israel. NBER Working Paper 28312. https://doi.org/10.3386/W28312

Gupta, S., \& Gentry, J. W. (2016). The behavioral responses to perceived scarcity-the case of fast fashion. The International Review of Retail, Distribution and Consumer Research, 26(3), 260-271. https://doi.org/10.1080/09593969.2016.1147476

Hardy, B. L., \& Logan, T. D. (2020). Racial economic inequality amid the COVID-19 crisis (the hamilton project). Retrieved from https://search.bvsalud.org/global-literature-on-novel-coronavirus2019-ncov/resource/en/grc-740305.

Hasell, J. (2020). Which countries have protected both health and the economy in the pandemic? Our World in Data. Retrieved from https://ourworldindata.org/covid-health-economy.

Heflin, C. (2016). Family instability and material hardship: Results from the 2008 survey of income and program participation. Journal of Family and Economic Issues, 37(3), 359-372. https://doi. org/10.1007/s10834-016-9503-6

Heflin, C., \& Iceland, J. (2009). Poverty, material hardship, and depression. Social Science Quarterly, 90(5), 1051-1071. https://doi.org/ 10.1111/j.1540-6237.2009.00645.x

Hurd, M. D., Rohwedder, S., Diaz, C., Malchiodi, A., \& Outcault, S. (2010). Effects of the financial crisis and great recession on American households. Retrieved from http://www.nber.org/ papers/w16407.

Kang, I., He, X., \& Shin, M. M. (2020). Chinese consumers' herd consumption behavior related to Korean luxury cosmetics: The mediating role of fear of missing out. Frontiers in Psychology, 11(121), 121. https://doi.org/10.3389/FPSYG.2020.00121

Kemp, E., Kennett-Hensel, P. A., \& Williams, K. H. (2014). The calm before the storm: Examining emotion regulation consumption in the face of an impending disaster. Psychology \&amp; Marketing, 31(11), 933-945. https://doi.org/10.1002/MAR.20744

Kochhar, R. (2020). Unemployment rose higher in three months of COVID-19 than it did in two years of the great recession. Retrieved from https://www.pewresearch.org/fact-tank/2020/06/ 11/unemployment-rose-higher-in-three-months-of-covid-19-thanit-did-in-two-years-of-the-great-recession.

Kondratjeva, O., Schwartz-Tayri, T., Bufe, S., Roll, S., Gal, J., \& Grinstein-Weiss, M. (2021). Did government benefits help Israeli households avoid hardship during COVID-19? Evidence from a national survey. Social Policy Institute Research.

KPMG. (2020). Government and institution measures in response to COVID-19. Retrieved from: https://home.kpmg/xx/en/home/insig hts/2020/04/israel-government-and-institution-measures-in-respo nse-to-covid.html

Krueger, D., Mitman, K., \& Perri, F. (2016). On the distribution of the welfare losses of large recessions. National Bureau of Economic Research. https://doi.org/10.3386/W22458
Latet. (2020). Dysfunctional reality - The annual poverty report. Tel-Aviv, Israel: Latet. Retrieved from: https://www.latet.org.il/ upload/files/162255307060b631ee8f131901250.pdf

Laufer, S., Haran-Rosen, M., \& Somekh, S. (2020). Employment, income and household finances in Israel during the COVID-19 pandemic. Jerusalem, Israel: Myers-JDC-Brookdale Institute.

Lequiller, F., \& Blades, D. (2014). Understanding national accounts (2nd ed.). OECD Publishing.

Long, H., Van Dam, A., Fowers, A., \& Shapiro, L. (2020). The COVID-19 recession is the most unequal in modern U.S. history. In The Washington Post. Retrieved from https://www.washington post.com/graphics/2020/business/coronavirus-recession-equality/.

Loxton, M., Truskett, R., Scarf, B., Sindone, L., Baldry, G., \& Zhao, Y. (2020). Consumer behaviour during crises: Preliminary research on how coronavirus has manifested consumer panic buying, herd mentality, changing discretionary spending and the role of the media in influencing behaviour. Journal of Risk and Financial Management, 13(8), 166. https://doi.org/10.3390/JRFM13080166

McKinsey \& Company. (2020). Consumer sentiment and behavior continue to reflect the uncertainty of the COVID-19 crisis. McKinsey \& Company. Retrieved from: https://www.mckinsey.com/busin ess-functions/marketing-and-sales/our-insights/a-global-viewof-how-consumer-behavior-is-changing-amid-covid-19

Mian, A., Rao, K., \& Sufi, A. (2013). Household balance sheets, consumption, and the economic slump*. The Quarterly Journal of Economics, 128(4), 1687-1726. https://doi.org/10.1093/QJE/ QJT020

Ministry of Health. (2020a). From Sunday morning, it is mandatory to wear masks outside the home. Ministry of Health.

Ministry of Health. (2020b). The government approved emergency regulations to restrict activities in order to curb the spread of coronavirus in Israel.

Morales, D. X., Morales, S. A., \& Beltran, T. F. (2020). Racial/ethnic disparities in household food insecurity during the COVID19 pandemic: A nationally representative study. Journal of Racial and Ethnic Health Disparities. https://doi.org/10.1007/ s40615-020-00892-7

Moss, K., Dawson, L., Long, M., Kates, J., Musumeci, M., Cubanski, J., \& Pollitz, K. (2020). The families first coronavirus response act: Summary of key provisions. KFF.

National Association of Regulatory Utility Commissioners. (2021). Map of disconnection moratoria. Retrieved from https://www. naruc.org/compilation-of-covid-19-news-resources/map-of-disco nnection-moratoria/.

National Insurance Institute. (2020). Unemployment benefits following the Corona crisis-all information.

Olsson, U. (1979). Maximum likelihood estimation of the polychoric correlation coefficient. Psychometrika. https://doi.org/10.1007/ BF02296207

Organization for Economic Cooperation and Development. (2015). Education at a glance 2015: OECD Indicators-Israel (education at a glance). $O E C D$. https://doi.org/10.1787/EAG-2015-EN

Organization for Economic Cooperation and Development. (2020a). COVID-19: Protecting people and societies. https://doi.org/10. 1787/9870c393-en

Organization for Economic Cooperation and Development. (2020b). General assessment of the macroeconomic situation. OECD Economic Outlook. https://doi.org/10.1787/39a88ab1-en

Organization for Economic Cooperation and Development. (2020c). OECD Economic Surveys-Israel.

Organization for Economic Cooperation and Development. (2021a). Income inequality (indicator).

Organization for Economic Cooperation and Development. (2021b). Poverty rate (indicator). 
Organization for Economic Cooperation and Development. (2021c). Unemployment rate indicator. https://doi.org/10.1787/52570 002-en

Parker, K., Minkin, R., \& Bennett, J. (2020). Economic fallout from COVID-19 continues to hit lower-income americans the hardest. Retrieved from https://www.pewsocialtrends.org/wp-conte nt/uploads/sites/3/2020/09/SDT_2020.09.24_COVID-19-Perso nal-Finances_FINAL.pdf.

Petev, I. D., \& Pistaferri, L. (2012). Consumption in the great recession. The Russell Sage Foundation and The Stanford Center on Poverty and Inequality. Retrieved from: https://inequality.stanford. edu/sites/default/files/Consumption_fact_sheet.pdf

Pilkauskas, N. V., Currie, J. M., \& Garfinkel, I. (2012). The great recession, public transfers, and material hardship. Social Service Review, 86(3), 401-427. https://doi.org/10.1086/667993

Rauh, V. A., Whyatt, R. M., Garfinkel, R., Andrews, H., Hoepner, L., Reyes, A., Diaz, D., Camann, D., \& Perera, F. P. (2004). Developmental effects of exposure to environmental tobacco smoke and material hardship among inner-city children. Neurotoxicology and Teratology, 26(3), 373-385. https://doi.org/10.1016/j.ntt.2004.01. 002

Ritchie, H., Mathieu, E., Rodés-Guirao, L., Appel, C., Giattino, C., Ortiz-Ospina, E., Hasell, J., Macdonald, B., Beltekian, D., \& Roser, M. (2021). Coronavirus pandemic (COVID-19). Our World in Data. https://ourworldindata.org/coronavirus.

Roll, S., Bufe, S., Chun, Y., \& Grinstein-Weiss, M. (2021). The socioeconomic impacts of COVID-19 study: Survey methodology report, Vol. 54. Social Policy Institute Research. Retrieved from: https://openscholarship.wustl.edu/spi_research/54

Roll, S., \& Despard, M. (2020). Income loss and financial distress during COVID-19: The protective role of liquid assets. Available at SSRN 3733862.

Roll, S., \& Grinstein-Weiss, M. (2020). Did CARES Act benefits reach vulnerable Americans? Evidence from a national survey. Brookings Report. Retrieved from: https://www.brookings.edu/resea rch/did-cares-act-benefits-reach-vulnerable-americans-evidencefrom-a-national-survey/

Social Policy Institute. (2020). The far-reaching impacts of COVID19 on the financial lives of Israelis-differences by religion and ethnicity. Retrieved from https://socialpolicyinstitute.wustl.edu/ the-far-reaching-impacts-of-covid-19-on-the-financial-lives-ofisraelis-differences-by-religion-and-ethnicity/

Searle, B. A., \& Köppe, S. (2014). Assets, savings and wealth, and poverty: A review of evidence. Final report to the Joseph Rowntree Foundation. Bristol: Personal Finance Research Centre.

Sheu, J. B., \& Kuo, H. T. (2020). Dual speculative hoarding: A wholesaler-retailer channel behavioral phenomenon behind potential natural hazard threats. International Journal of Disaster Risk Reduction, 44, 101430. https://doi.org/10.1016/J.IJDRR.2019. 101430

Sneath, J. Z., Lacey, R., \& Kennett-Hensel, P. A. (2008). Coping with a natural disaster: Losses, emotions, and impulsive and compulsive buying. Marketing Letters, 20(1), 45-60. https://doi.org/10.1007/ S11002-008-9049-Y

Tomer, A., \& Kane, J. W. (2020). To protect frontline workers during and after COVID-19, we must define who they are. Washington, DC: Brookings Institute. Retrieved from: https:// www. brookings.edu/research/to-protect-frontline-worke rs-during-and-after-covid-19-we-must-define-who-they-are/

Treasury Department. (2021). The treasury department is delivering COVID-19 relief for All Americans. U.S. Department of the Treasury.

Triggs, A., \& Kharas, H. (2020). The triple economic shock of COVID19 and priorities for an emergency $G-20$ leaders meeting. Retrieved from https://www.brookings.edu/wp-content/uploads/ 2020/09/FutureShutdowns_Facts_LO_Final.pdf.
Tsao, Y. C., Raj, P. V. R. P., \& Yu, V. (2019). Product substitution in different weights and brands considering customer segmentation and panic buying behavior. Industrial Marketing Management, 77, 209-220. https://doi.org/10.1016/J.INDMARMAN.2018.09.004

U.S. Census Bureau. (2021). American community survey data. Retrieved from https://www.census.gov/programs-surveys/acs/ data.html.

United Nations Department of Economic and Social Affairs. (2011). The Global Social Crisis. United Nations.

USDA Economic Research Service. (2012). U.S. household food security survey module: Six-item short form. Retrieved from https:// www.ers.usda.gov/media/8282/short2012.pdf.

Whittle, H. J., Palar, K., Hufstedler, L. L., Seligman, H. K., Frongillo, E. A., \& Weiser, S. D. (2015). Food insecurity, chronic illness, and gentrification in the San Francisco Bay Area: An example of structural violence in United States public policy. Social Science and Medicine, 143, 154-161. https://doi.org/10.1016/j.socscimed. 2015.08.027

World Bank. (2019). Population, female (\% of total population)Israel. Retrieved from https://data.worldbank.org/indicator/SP. POP.TOTL.FE.ZS?locations=IL.

Yuen, K. F., Wang, X., Ma, F., \& Li, K. X. (2020). The psychological causes of panic buying following a health crisis. International Journal of Environmental Research and Public Health, 17(10), 3513. https://doi.org/10.3390/IJERPH17103513

Zack, E. S., Kennedy, J. M., \& Long, J. S. (2019). Can nonprobability samples be used for social science research? A cautionary tale. Survey Research Methods, 13(2), 215-227. https://doi.org/10. 18148/srm/2019.v13i2.7262

Publisher's Note Springer Nature remains neutral with regard to jurisdictional claims in published maps and institutional affiliations.

Stephen Roll is a Research Assistant Professor at the Social Policy Institute and the Brown School at Washington University in St. Louis. His research focuses on promoting asset building, debt management, and economic security in lower-income populations. In addition, he is involved in research on child savings, food insecurity, and the role of financial technology services in promoting financial well-being. His work often involves applying a behavioral lens to social policy issues.

Yung Chun is a Data Analyst III at the Social Policy Institute. Through his various academic backgrounds spanning Architecture Engineering, Urban Planning, and Public Policy, he has researched housing markets and policy focusing on housing finance and homeownership. In addition, he is recently involved in research on the impacts of COVID-19 on U.S. families, and socioeconomically marginalized population in particular. He received his Ph.D. in Public Affairs from John Glenn College of Public Affairs at The Ohio State University.

Olga Kondratjeva is a program evaluation specialist at the Washington State Employment Security Department and a data analyst with the Social Policy Institute at Washington University in St. Louis. She is broadly interested in the topics of financial inclusion, financial capability, and asset building. She has been involved in a number of projects examining issues in financial security and financial well-being in the U.S. population. In addition, her work with SPI has included conducting research on the universal child savings program in Israel. She earned her Ph.D. in Public Policy and Management from The Ohio State University, where her dissertation explored the relationship between borrowing from formal and informal financial institutions and household well-being in Nepal. 
Mathieu Despard is an Associate Professor in the Department of Social Work at UNC Greensboro, a Visiting Scholar with the Social Policy Institute at Washington University in St. Louis, an Adjunct Assistant Professor at the Kenan-Flagler Business School at UNC Chapel Hill, and a Faculty Associate with the Center on Assets, Education, and Inclusion at the University of Michigan. He conducts research on financial health and economic mobility with a focus on low- and moderate-income households, and on the capacity of nonprofit organizations serving these households.

Talia Meital Schwartz-Tayri is a faculty member at Ben Gurion University of the Negev. She completed her Ph. D. at Tel Aviv University and was a post-doctoral researcher at the University of California - Berkeley School of Social Welfare. Her research primarily focuses on the quality of social services, the assessment of national welfare programs, and predicting the resilience of families and individuals using big data.
Michal Grinstein-Weiss is the Director of the Social Policy Institute at Washington University in St. Louis, Shanti K. Khinduka Distinguished Professor, and Associate Dean for Policy Initiatives at the Brown School, and the Director of the Centene Center for Health Transformation housed within the Social Policy Institute. She also holds a position as a Nonresident Senior Fellow at the Brookings Institution. A leading expert in the asset-building field, Dr. Grinstein-Weiss is influential in the design of innovative policies to promote household financial security and social and economic mobility, both in the United States and internationally. She also develops and tests behavior-based healthcare interventions and has led successful large-scale research projects for federal, philanthropic, and industry partners. 